\title{
Evidence from the resurrected family Polyrhabdinidae Kamm, 1922 (Apicomplexa: Gregarinomorpha) supports the epimerite, an attachment organelle, as a major eugregarine innovation
}

\author{
Gita G. Paskerova ${ }^{\text {Corresp., } 1}$, Tatiana S. Miroliubova ${ }^{2}$, Andrea Valigurová ${ }^{3}$, Jan Janouškovec ${ }^{4}$, Magdaléna Kováčiková $^{3}$, \\ Andrei Diakin ${ }^{3}$, Yuliya Ya. Sokolova ${ }^{5}$, Kirill V. Mikhailov ${ }^{6,7}$, Vladimir V. Aleoshin ${ }^{6,7}$, Timur G. Simdyanov ${ }^{8}$ \\ 1 Department of Invertebrate Zoology, Faculty of Biology, St. Petersburg State University, St Petersburg, Russia \\ 2 Laboratory for Fauna and Systematics of Parasites, Center for Parasitology, Severtsov Institute of Ecology and Evolution, Russian Academy of Sciences, \\ Moscow, Russian Federation \\ 3 Department of Botany and Zoology, Faculty of Science, Masaryk University, Brno, Czech Republic \\ ${ }^{4}$ Centre Algatech, Institute of Microbiology of the Czech Academy of Sciences, Třeboň, Czech Republic \\ 5 Institute of Cytology, Russian Academy of Sciences, St Petersburg, Russian Federation \\ 6 Belozersky Institute for Physico-Chemical Biology, Lomonosov Moscow State University, Moscow, Russian Federation \\ 7 Kharkevich Institute for Information Transmission Problems, Russian Academy of Sciences, Moscow, Russian Federation \\ 8 Department of Invertebrate Zoology, Faculty of Biology, Lomonosov Moscow State University, Moscow, Russian Federation
}

Corresponding Author: Gita G. Paskerova

Email address: gitapasker@yahoo.com

Background. Gregarines are a major group of apicomplexan parasites of invertebrates. The gregarine classification is largely incomplete because it relies primarily on light microscopy, while electron microscopy and molecular data in the group are fragmentary and often do not overlap. A key characteristic in gregarine taxonomy is the structure and function of their attachment organelles (AOs). AOs have been commonly classified as "mucrons" or "epimerites" based on their association with other cellular traits such as septation. An alternative proposal focused on the AOs structure, functional role, and developmental fate has recently restricted the terms "mucron" to archigregarines and "epimerite" to eugregarines.

Methods. Light microscopy and scanning and transmission electron microscopy, molecular phylogenetic analyses of ribosomal RNA genes.

Results. We obtained the first data on fine morphology of aseptate eugregarines Polyrhabdina pygospionis and Polyrhabdina cf. spionis, the type species. We demonstrate that their AOs differ from the mucron in archigregarines and represent an epimerite structurally resembling that in other eugregarines examined using electron microscopy. We then used the concatenated ribosomal operon DNA sequences (SSU, 5.8S, and LSU rDNA) of $P$. pygospionis to explore the phylogeny of eugregarines with a resolution superior to SSU rDNA alone. The obtained phylogenies show that the Polyrhabdina clade represents an independent, deep-branching family in the Ancoroidea clade within eugregarines. Combined, these results lend strong support to the hypothesis that the epimerite is a synapomorphic innovation of eugregarines. Based on these findings, we resurrect the family Polyrhabdinidae Kamm, 1922 and erect and diagnose the family Trollidiidae fam. n. within the superfamily Ancoroidea Simdyanov et al., 2017. Additionally, we re-describe the characteristics of $P$. pygospionis, emend the diagnoses of the genus Polyrhabdina, the family Polyrhabdinidae, and the superfamily Ancoroidea. 
1 Evidence from the resurrected family Polyrhabdinidae Kamm, 1922 (Apicomplexa:

2 Gregarinomorpha) supports the epimerite, an attachment organelle, as a major

3 eugregarine innovation

4

\title{
Epimerite in eugregarines
}

Gita G. Paskerova ${ }^{1}$, Tatiana S. Miroliubova ${ }^{2}$, Andrea Valigurová ${ }^{3}$, Jan Janouškovec ${ }^{4}$, Magdaléna Kováčiková $^{3}$, Andrei Diakin ${ }^{3, \dagger}$, Yuliya Ya. Sokolova ${ }^{5}$, Kirill V. Mikhailov 6, 7 , Vladimir V. Aleoshin $^{6,7}$, Timur G. Simdyanov ${ }^{8}$

${ }^{1}$ Department of Invertebrate Zoology, Faculty of Biology, St Petersburg State University, St Petersburg, Russian Federation

${ }^{2}$ Laboratory for Fauna and Systematics of Parasites, Center for Parasitology, Severtsov Institute of Ecology and Evolution, Russian Academy of Sciences, Moscow, Russian Federation

${ }^{3}$ Department of Botany and Zoology, Faculty of Science, Masaryk University, Brno, Czech Republic

${ }^{4}$ Centre Algatech, Institute of Microbiology of the Czech Academy of Sciences, Třeboň, Czech Republic

${ }^{5}$ Institute of Cytology, Russian Academy of Sciences, St Petersburg, Russian Federation

${ }^{6}$ Belozersky Institute for Physico-Chemical Biology, Lomonosov Moscow State University, Moscow, Russian Federation

${ }^{7}$ Kharkevich Institute for Information Transmission Problems, Russian Academy of Sciences, Moscow, Russian Federation

${ }^{8}$ Department of Invertebrate Zoology, Faculty of Biology, Lomonosov Moscow State University, Moscow, Russian Federation

$\dagger$ deceased on 5 November 2018

Corresponding Author:

Gita G. Paskerova ${ }^{1}$

Universitetskaya emb. 7/9, St Petersburg 199034, Russian Federation

Email address: gitapasker@yahoo.com, g.paskerova@mail.spbu.ru

\begin{abstract}
Background. Gregarines are a major group of apicomplexan parasites of invertebrates. The gregarine classification is largely incomplete because it relies primarily on light microscopy, while electron microscopy and molecular data in the group are fragmentary and often do not overlap. A key characteristic in gregarine taxonomy is the structure and function of their attachment organelles (AOs). AOs have been commonly classified as "mucrons" or "epimerites" based on their association with other cellular traits such as septation. An alternative proposal focused on the AOs structure, functional role, and developmental fate has recently restricted the terms "mucron" to archigregarines and "epimerite" to eugregarines.

Methods. Light microscopy and scanning and transmission electron microscopy, molecular phylogenetic analyses of ribosomal RNA genes.

Results. We obtained the first data on fine morphology of aseptate eugregarines Polyrhabdina pygospionis and Polyrhabdina cf. spionis, the type species. We demonstrate that their AOs differ from the mucron in archigregarines and represent an epimerite structurally resembling that in
\end{abstract}


47

other eugregarines examined using electron microscopy. We then used the concatenated ribosomal operon DNA sequences (SSU, 5.8S, and LSU rDNA) of P. pygospionis to explore the phylogeny of eugregarines with a resolution superior to SSU rDNA alone. The obtained phylogenies show that the Polyrhabdina clade represents an independent, deep-branching family in the Ancoroidea clade within eugregarines. Combined, these results lend strong support to the hypothesis that the epimerite is a synapomorphic innovation of eugregarines. Based on these findings, we resurrect the family Polyrhabdinidae Kamm, 1922 and erect and diagnose the family Trollidiidae fam. n. within the superfamily Ancoroidea Simdyanov et al., 2017. Additionally, we re-describe the characteristics of $P$. pygospionis, emend the diagnoses of the genus Polyrhabdina, the family Polyrhabdinidae, and the superfamily Ancoroidea.

Subjects Cell Biology, Microbiology, Parasitology, Taxonomy, Zoology Keywords Eugregarinida, Intestinal parasites, Marine gregarines, Ultrastructure, SSU and LSU rDNA, Host-parasite relationships, Environmental DNA sequences, Phylogeny, Taxonomy

\section{Introduction}

Apicomplexa are a large and diverse group of unicellular eukaryotes, many of which are symbionts of invertebrate and vertebrate animals (Simdyanov et al., 2018). Gregarines appear to be a monophyletic group of apicomplexan parasites - class Gregarinomorpha Grassé, 1953 (Janouškovec et al., 2019). They are characterised by the pre-sexual association of gamonts (syzygy) and gametocyst production (Simdyanov et al., 2017). At present, gregarines include two groups: archigregarines (order Archigregarinida Grassé, 1953) which possess characters of plesiomorphic state and develop in the intestine of polychaetes and sipunculids, and eugregarines (order Eugregarinida Léger, 1900) which are parasites of the tissue, intestine and other cavities of diverse invertebrates (Adl et al., 2019; Desportes and Schrével, 2013; Simdyanov et al., 2017). Traditionally, gregarines also contained neogregarines, now a clearly polyphyletic mixture of eugregarines (Cavalier-Smith, 2014; Simdyanov et al., 2017), and blastogregarines, which can be either considered as a separate class due to the lack of the gametocyst and syzygy (Simdyanov et al., 2018) or the sister group of archigregarines (Janouškovec et al., 2019). Eugregarines have been classified by the morphology of their dominant trophozoite and gamont stages into two groups. Septate eugregarines (Septata Lankester, 1885) have a fibrillar septum subdividing their cell into anterior and nucleated posterior parts and predominately parasitize terrestrial invertebrates. Aseptate eugregarines (Aseptata Chakravarty, 1960) lack the septum and inhabit mostly marine invertebrates (Desportes and Schrével, 2013; Simdyanov, 2007). Molecular phylogenies show that this classification is not natural because septate eugregarines are polyphyletic (Cavalier-Smith, 2014; Simdyanov et al., 2017).

Molecular phylogenetic studies of gregarines are limited by the availability of reference sequences and are largely based on small subunit (SSU) ribosomal DNA (rDNA) sequences (e.g., Diakin et al., 2016; Rueckert et al., 2018; Wakeman and Leander, 2013; Wakeman et al., 2017). Since many gregarine SSU rDNA sequences form long branches in molecular phylogenies, both archi- and eugregarines were thought to be polyphyletic and possess characteristics of a convergent origin (e.g., Cavalier-Smith, 2014). However, recent studies that used the concatenated sequences of SSU and large subunit (LSU) rDNA genes have recovered relationships within Apicomplexa with a resolution superior to the analyses inferred from SSU rDNA alone and revealed gregarines as monophyletic (Paskerova et al., 2018; Simdyanov et al., $2015,2017,2018$ ). This conclusion was unambiguously supported by phylogenetic analyses 
based on 296 (Janouškovec et al., 2019) and 195 (Mathur et al., 2021) concatenated proteincoding genes. The observation that concatenated rDNA sequences perform better at resolving deep phylogenetic relationships in a group than SSU rDNA alone is receiving increasing support in studies of protist diversity (Jamy et al., 2019).

Most gregarines are extracellular parasites which attach with an attachment organelle (AO) to one or several host cells. The AO is commonly classified as "mucron" or "epimerite" depending on whether the gregarine is aseptate or septate, respectively (Levine, 1971). Reassessing the organization, function, and developmental fate of the $\mathrm{AO}$ in gregarine microscopy literature and in the aseptate eugregarine Ancora sagittata (Leuckart, 1860) Labbé, 1899, Simdyanov et al. (2017) proposed to restrict the term "epimerite" to the AO in eugregarines and the term "mucron" to the AO in archigregarines. The epimerite is an anchoring organelle, originated de novo in front of the trophozoite anterior end, varying in size and shape, and usually lost in the gamont. The mucron represents the hypertrophied anterior end of the trophozoite and gamont and is usually small, rounded or sucker-shaped.

In this study, we test the hypothesis that the epimerite is a synapomorphic trait of eugregarines. For this, we (1) studied the AO structure in the aseptate eugregarine Polyrhabdina pygospionis Caullery et Mesnil, 1914 parasitizing the polychaete Pygospio elegans; (2) compared fine morphology of $P$. pygospionis to that of Polyrhabdina $\mathrm{cf}$. spionis, the type species from Malacoceros fuliginosus; and (3) resolved phylogenetic relationships of $P$. pygospionis with other groups of aseptate gregarines within the order Eugregarinida, using the analyses of sequences of concatenated ribosomal operon genes (SSU, 5.8S, and LSU rDNA). Our analyses revealed a new deep branching clade of aseptate eugregarines with the epimerite-type AO. This clade resurrects the family Polyrhabdinidae Kamm, 1922 and belongs to the superfamily Ancoroidea Simdyanov et al., 2017.

\section{Materials \& Methods}

\section{Collection of polychaete hosts and isolation of gregarines}

Bristle worms Pygospio elegans Claparède, 1863 (Spionidae, Polychaeta) were collected at two sites of the littoral zone near the Marine Biological Station of St Petersburg State University (Bolshoy Goreliy Island, Keret' Archipelago, Chupa Inlet, Kandalaksha Bay, White Sea, $\left.66^{\circ} 18.770^{\prime} \mathrm{N} ; 33^{\circ} 37.715^{\prime} \mathrm{E}\right)$ and at the White Sea Biological Station of Lomonosov Moscow State University (Velikaja Salma strait, Kandalaksha Bay, White Sea, 663․ $33.200^{\prime}$ N, $33^{\circ} 6.283^{\prime}$ E) in the summer of 2002 - 2018. Polychaetes Malacoceros fuliginosus (Claparède, 1868) (Spionidae, Polychaeta) were collected under stones at the intertidal zone near the Roscoff

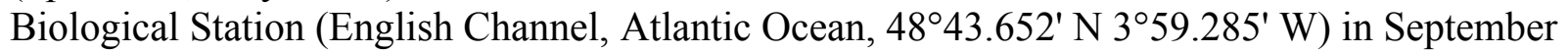
2010.

The examined animals were stored and dissected for isolation of parasites according to Paskerova et al. (2018). The released parasites or small fragments of the host intestine with attached gregarines were rinsed three times in seawater filtered through Millipore $(0.22 \mu \mathrm{m})$, then fixed for electron microscopy.

\section{Light microscopy}

More than 100 polychaetes of $P$. elegans were investigated in squash preparations with living parasites (Fig. 1A, D-H). Separate eugregarines isolated from the host intestines were also investigated in living preparations (Fig. 1B-C, Supplementary Material SVideo). The microscopes used for observation were Leica DM2500 equipped with DIC optics, Plan-Apo 
139

140

141

142

143

144

145

146

147

148

149

150

151

152

153

154

155

156

157

158

159

160

161

162

163

164

165

166

167

168

169

170

171

172

173

174

175

176

177

178

179

180

181

182

183

objective lenses, and DFC 295 digital camera (Leica, Germany); MBR-1 (LOMO, Russia) equipped with phase contrast and Canon EOS 300D digital camera; Zeiss Axio Imager.A1 equipped with phase contrast and DIC optics and Axio-Cam MRc5 digital camera (Carl Zeiss, Germany). Maximal dimensions of gregarine cells were measured with the ImageJ program (rsb.info.nih.gov/ij/); average (av) and standard deviation (SD) values were calculated (Supplementary Material STable 1).

\section{Electron microscopy}

For scanning (SEM) and transmission (TEM) electron microscopy, small pieces of the polychaete intestine with attached eugregarines or free eugregarines released from the host gut lumen were fixed in $2.5 \%$ glutaraldehyde in $0.2 \mathrm{M}$ cacodylate buffer ( $\mathrm{pH} 7.4$, final osmolarity $720 \mathrm{mOsm}$ ) for $2 \mathrm{~h}$, washed in filtered seawater and postfixed in $2 \%$ osmium tetroxide in the same buffer for $2 \mathrm{~h}$ (Fig. 2A-H; 3A-D; 4A-D). For visualisation of the glycocalyx and other mucosubstances, the samples were additionally fixed with $3 \%$ glutaraldehyde-ruthenium red $[0.15 \%(\mathrm{w} / \mathrm{v})$ stock water solution] in $0.2 \mathrm{M}$ cacodylate buffer $(\mathrm{pH} 7.4)$ and post-fixed with $1 \%$ OsO4-ruthenium red in the same buffer (Fig. 2I-J; 3E-G). Fixation was performed at $+4 \circ \mathrm{C}$. Fixed samples were dehydrated in an ascending ethanol series. For SEM, the fixed and dehydrated samples were critical point dried in liquid $\mathrm{CO}_{2}$ and then coated with gold or platinum. The samples were investigated with GEMINI Zeiss Supra 40VP (Carl Zeiss, Germany) and JSM$7401 \mathrm{~F}$ (JEOL, Japan) scanning electron microscopes. In total, more than 50 individuals of each species, $P$. pygospionis and $P$. cf. $P$. spionis, were examined by SEM. For TEM, samples of $P$. pygospionis, additionally dehydrated in an ethanol/acetone mixture and rinsed in pure acetone, were embedded in Epon-Araldite or Epon blocks. They were sectioned with ultramicrotomes Leica EM UC6 and Leica EM UC7 (Leica, Germany). Ultrathin sections were stained according to standard protocols and examined with LEO 910 (Carl Zeiss, Germany), JEM 2100 (JEOL, Japan), and JEM-1010 (JEOL, Japan) electron microscopes equipped with digital or film cameras. In total, more than 15 individuals of $P$. pygospionis were entirely sectioned and examined by TEM.

\section{Polyrhabdina rRNAs assembly}

The rRNA of $P$. pygospionis was assembled from transcriptomic data generated from about 19 parasite cells isolated from five $P$. elegans polychaetes which were collected at Velikaya Salma strait, Kandalaksha Bay, White Sea, in 2016 (Janouškovec et al., 2019). Assembled, highcoverage transcripts corresponding to $P$. pygospionis ribosomal RNA were identified by BLASTN homology searches and joined at overlaps into eight larger contigs. Raw transcriptomic reads mapping onto the eight rRNA contigs were retrieved in Bowtie 2 (default settings) and used for extension of the contigs in Consed v29 with the following crossmatch parameters: -minmatch 50 -minscore 50 -penalty -9 . Repeating this process in several iterations allowed us to merge and subsequently validate the complete rRNA operon sequence of $P$. pygospionis (comprising the SSU, ITS1, 5.8S, ITS2, and LSU). The final sequence was deposited into GenBank under the accession number MT214481.

We did not isolate DNA from $P$. cf. spionis cells because we found a limited number of cells, mostly of which were fixed for electron microscopy (see Results).

\section{Molecular phylogenetic analysis}


184 The rDNA dataset for phylogenetic analyses was constructed using publicly available sequence 185 data and designed to maximize the diversity of eugregarines at the family level. Unidentified 186 environmental sequences and rDNA contigs from metagenome assemblies were found by 187 BLAST searches (Altschul et al., 1997) in the nr and wgs databases of NCBI. Small set of 188 Coccidiomorpha (Coccidia and Hematozoa) species was used as an outgroup in the phylogenetic 189 analyses.

Three datasets were prepared for phylogenetic analyses: taxonomically balanced SSU concatenated dataset with SSU, 5.8S, and LSU rDNA sequences (31 OTUs). The datasets were aligned in MUSCLE 3.6 (Edgar, 2004) and manually adjusted with BioEdit 7.0.9.0 (Hall, 1999): gaps, columns containing few nucleotides or hypervariable regions (V2, V4, V7, and V9) were removed, which resulted in 1,574-site (SSU) and 4,571-site (concatenated) alignments. To verify the results of manual masking, we additionally used two different automatic alignment and masking strategies for the SSU datasets. With the first strategy, the alignment of SSU rDNA sequences was done with MAFFT (Katoh and Standley, 2013) using a combination of local and structural alignments: the initial draft alignment was prepared using the local alignment with generalized affine gap cost (E-INS-i), the variable gap-rich regions were then aligned individually with the secondary structure aware alignment (X-INS-i) employing MXSCARNA (Tabei et al., 2008) to produce the final alignment. Prior to analyses the alignment was masked with trimAl (Capella-Gutierrez et al., 2009) using a gap threshold of 0.5 and a minimum block size of 3; the result was a 1578-site alignment. The second strategy employed the GUIDANCE2 web server (Landan and Graur, 2008; Penn et al., 2010; Sela et al., 2015) and MAFFT (E-INS-i) to generate a series of alignments with varying confidence score thresholds. Columns with confidence scores below $0.715,0.794,0.900,0.942,0.970,0.973$, and 0.990 were removed resulting in 1,574, 1,471, 1,366, 1,257, 1,126, 1,087 and 828-site long alignments, respectively. To obtain a similar series for the alignment generated using the first strategy, we calculated sitespecific evolutionary rates with IQ-TREE 2.1.2 (Minh et al., 2020) and preformed stepwise removal of sites starting with the fastest category.

Maximum-likelihood (ML) analyses were performed with IQ-TREE 2.1.2 (Minh et al., 2020) using non-parametric bootstrap (-b 1000) and ultrafast bootstrap approximation (UFBoot, bb 1000) (Minh et. al., 2013) employing the CIPRES Science Gateway (Miller et al., 2010). Bayesian inference (BI) analyses were done with MrBayes 3.2.6 (Ronquist et al., 2012), PhyloBayes (Lartillot et al., 2013), and Phycas 2.2 (Lewis et al., 2015). Evolutionary models for ML and Bayesian analyses were selected with ModelFinder (Kalyaanamoorthy et al., 2017): the $\mathrm{GTR}+\mathrm{F}+\mathrm{I}+\mathrm{G} 8$ model was selected for the SSU rDNA datasets, and the SSU and LSU partitions in the concatenated dataset, while the GTR+F+G8 model was selected for the 5.8S partition. The following parameters of Metropolis Coupled Markov Chain Monte Carlo ( $\mathrm{mcmcmc})$ were used: nchains $=8$, nruns $=2$, temp $=0.025$, ngen $=5,000,000$, samplefreq $=1,000$, burninfrac $=0.5$. The average standard deviations of split frequencies at the end of BI (MrBayes) computations were 0.005044 for the 94 OTU dataset, 0.012636 for the 65 OTU dataset, and 0.003799 for the 31 OTU dataset. The ML support values were assigned to the SSU Bayesian tree using 1000 non-parametric bootstrap trees from the ML analysis via the -sup option of IQ-TREE 2.1.2 (Minh et al., 2020). Additional BI analysis of full manually masked SSU alignment (1574 bp) was performed with PhyloBayes (Lartillot er al., 2013) under the GTR+ G8+CAT model (four chains, 20000 cycles, the first half of sample points were discarded as burn-in). Constrained tree 
229

230

231

232

233

234

235

236

237

238

239

240

241

242

243

244

245

246

247

248

249

250

251

252

253

254

255

256

257

258

259

260

261

262

263

264

265

266

267

268

269

270

271

272

273

search and approximately unbiased (AU) tests were performed with IQ-TREE 2.1.2 (Minh et al., 2020).

Differences in the ML trees obtained with X-INS-i, GUIDANCE2 or full manually masked alignments were outlined by means of the principal component analysis (PCA). Using the bpcomp program of PhyloBayes, the ML trees were represented as sets of bipartitions with the corresponding bipartition support values treated as variables for PCA. For the analysis we used the support values calculated with UFBoot by IQ-TREE. The set of tree bipartitions used for PCA was reduced from the initial full set to just 146 bipartitions, representing only the interrelationships of main gregarine groups - groups that were well-supported by all analyses. The PCA was performed using R (R Core Team, 2021) and R packages FactoMineR (Lê et al., 2008), factoextra, and ggplot2 (Wickham, 2016).

The secondary structure of helix 17 (numbering according to Wuyts et al., 2001) of SSU rRNA was predicted using the Mfold server (Zuker, 2003) at http://www.unafold.org/mfold/applications/rna-folding-form.php.

\section{New Zoological Taxonomic Names}

The electronic version of this article in Portable Document Format (PDF) will represent a published work according to the International Commission on Zoological Nomenclature (ICZN), and hence the new names contained in the electronic version are effectively published under that Code from the electronic edition alone. This published work and the nomenclatural acts it contains have been registered in ZooBank, the online registration system for the ICZN. The ZooBank LSIDs (Life Science Identifiers) can be resolved and the associated information viewed through any standard web browser by appending the LSID to the prefix http://zoobank.org/. The LSID for this publication is: urn:lsid:zoobank.org:pub:693369E6-B319-4BB1-8E61148FC4F5B271. The online version of this work is archived and available from the following digital repositories: PeerJ, PubMed Central SCIE and CLOCKSS.

\section{Results \\ Polyrhabdina pygospionis Occurrence}

Eugregarines P. pygospionis were found in the intestine of 126 out of 302 (42\%) examined Pygospio elegans polychaetes (Spionidae). The intensity of infection usually varied from 1 to 50 (mode 1, average (av.) 6) gregarines per host. Parasites $P$. pygospionis co-occurred with other symbionts, archigregarines Selenidium pygospionis Paskerova et al., 2018, in the gut of 66 polychaetes $(52 \%)$ versus 60 worms $(48 \%)$ infected only by eugregarines. From the life cycle stages, trophozoites (attached eugregarines) and gamonts (non-attached eugregarines) were found in the host intestine.

\section{General and fine structure}

The cell shape of gamonts varied from ellipsoid sometimes slightly curved to pear-shaped. Gamonts were circular in cross section, with rounded anterior and posterior ends. No septum was observed (Fig. 1A- F, 2A, F; Supplementary Material STable 1). Gamonts had a large, oval or almost spherical nucleus positioned longitudinally in the widest part of the cell, usually closer to the anterior end. In large gamonts, one large spherical nucleolus was observed in the nucleus (Fig. 1A-B). In small gamonts, two to four spherical nucleoli of diverse sizes were situated at 
274

275

276

277

278

279

280

281

282

283

284

285

286

287

288

289

290

291

292

293

294

295

296

297

298

299

300

301

302

303

304

305

306

307

308

309

310

311

312

313

314

315

316

317

318

opposing nuclear poles (Fig. 1E-F). Gamonts moved by gliding without obvious changes in the cell shape (Supplementary Material SVideo).

The cell surface of gamonts had numerous longitudinal epicytic crests (or folds; in this study, we use the terminology of Simdyanov et al. (2017)). They were almost straight (Fig. 1G; 2A-B) or undulated (Fig. 1H;2C). At the parasite ends, epicytic crests passed into smooth areas, usually smaller at the anterior end and larger at the posterior one (Fig. 2D-E). The cortex organization of the finger-like crests was typical of eugregarines: a three-membrane pellicle of 32-36 nm thick consisting of the plasma membrane and IMC. The pellicle was covered by a cell coat (glycocalyx) of about $10 \mathrm{~nm}$ and underlain by the internal lamina, an electron-dense fibrillar layer (Fig. 2F-J). The internal lamina of 17-23 nm thick formed additional loops under the bottom of grooves between the epicytic crests. No links in the base of each crest were visible, due to which the crest cytoplasm communicates freely with the bulk of the cell cytoplasm (Fig. $2 \mathrm{G}, \mathrm{I}$ ). In the crest tip, there were 10-12 apical rippled dense structures (apical arcs) between the plasma membrane and the IMC as well as 10-12 apical 12-nm filaments under the IMC (Fig. 2J). Micropores typical for apicomplexans were present on lateral walls of epicytic crests (Fig. 2GH). Electron-dense material, presumably excreted mucus, was observed in between crests in some epicyte regions of parasite cells (Fig. 2G). In Polyrhabdina cells, the ectoplasm, a peripheral cytoplasm layer free of amylopectin, and the endoplasm, the bulk cytoplasm enriched with rounded amylopectin granules, were not distinctly separated (Fig. 2F). The thickness of the ectoplasm varied from 0.2 to $0.6 \mu \mathrm{m}$ in the middle cell region; anterior and posterior zones of ectoplasm were usually equally sized.

The trophozoites were anchored in the host intestinal epithelium by a dome-shaped AO (Fig. 3A-C; Supplementary Material STable 1). Rarely, this organelle was also observed in gamonts (Fig. 1C-D). The AO in trophozoites was almost entirely embedded into a deep invagination of the host epithelial cell. A circular fold facing posteriorly - the collar - was presented at the base of the AO (Fig. 1D). This collar was located above the apical surface of the host cell and limited the area of AO insertion into the host cell invagination (Fig. 3B-D). Epicytic crests started from the AO base under the collar (Fig. 3C). Trophozoites mechanically dislodged from the intestinal epithelium during material preparation had an $\mathrm{AO}$ with a damaged apical surface corresponding to the host-parasite attachment site (Fig. 3B). The intact AO was covered only by the parasite plasma membrane, and the IMC terminated at the AO base (Fig. 3D-G). The attachment site had an appearance of a tight cell junction without a distinct gap between plasma membranes of the $\mathrm{AO}$ and host cell. Both membranes were underlain by electron-dense areas of fibrillar-like appearance (Fig. 3D-G). The collar represented a thin extension of the AO and was covered by the parasite plasma membrane (Fig. 3D, F). The cytoplasm of the $\mathrm{AO}$ was distinctly differentiated into two zones: a finely granular cortical zone located peripherally under the plasma membrane and within the collar, and a vesicular zone positioned in the centre and having occasional organelles typical for the rest of the parasite body, e.g., amylopectin granules (Fig. 3D, E). The infected host cell formed a thin circular fold at its apical surface. This fold consisted of two closely adjacent plasma membranes almost without any cytoplasm in between them and tightly surrounded the epimerite collar of the attached parasite (Fig. 3D). The distal end of the host circular fold was embedded in a gap of about $45 \mathrm{~nm}$ width and $600 \mathrm{~nm}$ depth located circularly at the base of the parasite AO under the collar. In the parasite cytoplasm, this circular gap was underlain by a fibrillar layer - the endpoint of the IMC. The terminus of the internal lamina was located under this layer (Fig. 3D inset, F). The ectoplasm of this region contained 
319

320

321

322

323

324

325

326

327

328

329

330

331

332

333

334

335

336

337

338

339

340

341

342

343

344

345

346

347

348

349

350

351

352

353

354

355

356

357

358

359

360

361

362

363

364

granular material with short fibrils mainly congregated near the termini of the internal lamina and IMC (Fig. 3D-F).

According to our observation on living P. pygospionis cells, during mechanical AO separation from the parasite cell, the edges of the anterior end seem to be pulled together and sometimes only a small part of the cytoplasm escaped (Supplementary Material SVideo). The wound surface was probably sealed by the granular cytoplasm with short fibrils located in the AO base (Fig. 1D inset; Supplementary Material SFigure 1A). The fine structure of the anterior end of recently detached gamonts corresponded to our in vivo observations (Supplementary Material SFigure 1B). In some parasites mechanically separated from the host cell by the pressure of a coverslip, long tensile cords were derived from the epimerite cytoplasm and the underlying ectoplasm (Fig. 1F). Basing on these obtained data, we presume that $P$. pygospionis gamonts usually discard their epimerites and, as a result, detach from the host tissue.

All parasitized host cells had an altered appearance: near the host-parasite contact zone, they had electron-dense, organelle-depleted cytoplasm with vesicles containing material of heterogeneous electron density, sometimes surrounded by an additional membrane (Fig. 3D). This may be considered as a host response to the gregarine infection.

Some examined eugregarines $P$. pygospionis were infected with microsporidia Metchnikovella incurvata Caullery and Mesnil, 1914 and M. spiralis Sokolova et al., 2014 (Supplementary Material SFigure 1A-B). Interestingly, these microsporidia also occupied the $\mathrm{AO}$ of infected gregarines (not shown).

\section{Polyrhabdina cf. spionis (von Kölliker, 1845) Mingazzini, 1891 Occurrence}

Eugregarines $P$. cf. spionis were found in the intestine of 3 out of 18 (17\%) Malacoceros fuliginosus polychaetes (Spionidae). One worm was relatively heavily infected, about 50 parasites per host, while others had only several eugregarines. From the life cycle stages, mainly trophozoites were found in the host intestine.

\section{General morphology}

Trophozoites were spindle- or rhomboid-shaped, wide in the cell middle and with a rounded posterior end (Fig. 4A; Supplementary Material STable 1). A single rounded nucleus was in the widest part of the cell (not shown). Trophozoites were anchored in the intestinal epithelium by a globular AO with the collar around its base (Fig. 4B-D). In some individuals, the collar was located above the apical surface of the host cell (Fig. 4A). The cell surface of parasites was covered with longitudinal epicytic crests, straight or slightly undulated. Epicytic crests started from the AO base under the collar (Fig. 4B). The parasites moved by gliding (not shown).

\section{Phylogenies inferred from rDNA sequences}

SSU rDNA phylogenies inferred by the Bayesian inference (BI) in MrBayes (Fig. 5) and Phycas and by the Maximum-likelihood (ML) analyses (not shown) using the full manually masked alignment showed almost identical topologies with a few minor differences. In both phylogenies, the sequence of Polyrhabdina pygospionis was placed in a robustly supported clade of 23 environmental sequences derived from marine sediments and one sequence derived from the foraminiferan Ammonia beccarii (see Discussion). This clade is subdivided into two subclades and is grouped with a clade consisting of Trollidium akkeshiense and five environmental sequences with high posterior probability $(\mathrm{PP}=1.0)$ but low non-parametric 
365

366

367

368

369

370

371

372

373

374

375

376

377

378

379

380

381

382

383

384

385

386

387

388

389

390

391

392

393

394

395

396

397

398

399

400

401

402

403

404

405

406

407

408

409

410

bootstrap percentage $(\mathrm{BP}=63 \%)$ supports. A clade containing Ancora sagittata and Polyplicarium species appears sister to the group with Polyrhabdina and Trollidium with statistically significant $\mathrm{PP}=0.98$, but low $\mathrm{BP}=40 \%$. BI analysis performed in PhyloBayes shows the same composition of Ancoroidea, but alternative topology with rearrangement of subclades within Polyrhabdinidae (Supplementary Material SFigure 2). The analyses of the concatenated dataset (SSU rDNA+5.8S rDNA+ LSU rDNA) improved the resolution of the tree (Fig. 6), however, the taxonomic sampling was reduced and the phylogenetic diversity of gregarines was lower (see Materials and Methods). The position of P. pygospionis did not change in this tree: it was still a sister taxon to Trollidium with moderate support $(\mathrm{PP}=0.95, \mathrm{BP}=79 \%)$. Importantly, the Trollidium-Polyrhabdina and Ancora dichotomy received stronger support as well ( $\mathrm{PP}=1, \mathrm{BP}$ $=90 \%$ ). Judging by the result of BI and the ML analyses, Polyrhabdina and relatives are presumably members of the superfamily Ancoroidea (see Discussion).

The Ancoroidea clade uniting Polyrhabdina pygospionis, Trollidium akkeshiense, Ancora sagittata, Polyplicarium spp., and related environmental sequences is consistently present in the ML trees based on the dataset constructed using structural alignment (X-INS-i) as well as with the derivative alignments after sequential deletion of rapidly evolving sites, supporting the results obtained with manually masked alignments (Supplementary Material SFigure 3). However, these phylogenies are generally in disagreement with the results obtained with the GUIDANCE2 alignments, which were generated with varying confidence score thresholds (Supplementary Material SFigure 3). The GUIDANCE2 trees show less reconciliation in the topology and composition of subclades for the Ancoroidea, which usually involve the clade of Trichotokara and Paralecudina, but not necessarily Trollidium. Close relationship of the Trichotokara + Paralecudina clade with Ancoroidea is also observed with the manually masked dataset if CAT model of molecular evolution implemented in PhyloBayes program is applied (Supplementary Material SFigure 3) or the most divergent sequences are excluded (65 OTUs) (Supplementary Material SFigure 4). In an attempt to resolve the discrepancy between the results of structural alignment and GUIDANCE2 experiments, we tested the possible composition of the Ancoroidea. We built constrained trees with four different subclade sets (including or excluding Trollidium, Trichotokara and Paralecudina, and Cephaloidophora) for full and 1471-site alignments generated with GUIDANCE2 and structural alignment, and performed AU tests (Supplementary Material STable 2). The AU tests did not reject the tested alternatives at the 5\% significance level, although the $p$-values were highly dependent on the alignment used. We also performed the PCA for resolving main differences in topologies generated using three different alignment and masking strategies (Supplementary Material SFigure 5). These differences were in Ancoroidea composition and Trichotokara +Paralecudina clade position, and some other systematic differences with a smaller contribution for these series of topologies. However, the PCA showed a preference for manual strategies as the obtained trees were more stable (red dots formed a denser group than green or blue ones in the data matrix, Supplementary Material SFigure 5).

A shared feature of most Polyrhabdinidae, Trollidium, and related environmental sequences was found in the predicted structure of helix 17 of the SSU rRNA (numbering according Wuyts et al., 2001). In most of these OTUs, the 3'-strand of helix 17 contains an additional nucleotide, forming a second bulge in the helix, while the typical state for eukaryotes is a single 1-nucleotide bulge in the 3'-strand (Supplementary Material SFigure 6). No similar structures of helix 17 have been found outside Polyrhabdinidae, Trollidium, and related environmental sequences, however, within the group the helix 17 is not constant and evolves

Peer] reviewing PDF | (2020:12:56148:1:1:NEW 27 Jun 2021) 
411 along the phylogenetic tree. This feature is an additional evidence for Polyrhabdina-Trollidium

412 relationships as the additional bulge in helix 17 was not included in any of the alignments used in 413 this research.

414

415

416

417

418

419

420

421

422

423

424

425

426

427

428

429

430

431

432

433

434

435

436

437

438

439

440

441

442

443

444

445

446

447

448

449

450

451

452

453

454

455

456

\section{Discussion}

\section{Polyrhabdina species and their taxonomic position}

The genus Polyrhabdina (original spelling Polyrabdina) was established by Mingazzini (1891) with Gregarina spionis Kölliker, 1848, a gregarine isolated from the polychaetes Scolelepis fuliginosa (Claparède, 1868) (now Malacoceros fuliginosa), as the type species. This genus was assigned to the family Lecudinidae Kamm, 1922 (Clopton, 2000; Ganapati, 1946; Grassé, 1953; Levine, 1971, 1977; Reichenow, 1929; Rueckert et al., 2018) or the family Polyrhabdinidae Kamm, 1922 (Desportes and Schrével, 2013; Kamm, 1922) depending on the emphasis given to gregarine septation and, correspondingly, AO naming - mucron or epimerite.

To date, the genus Polyrhabdina includes seven named species. One species has no description - Polyrhabdina sp. from Dipolydora socialis. All known Polyrhabdina spp. occur in the intestine of spionid polychaetes. All these species have been studied only using light and, in some cases, scanning electron microscopy (Caullery and Mesnil, 1897a, b, 1914a, 1919; von Kölliker, 1845, 1848; Mingazzini, 1891; Reichenow, 1932; Mackinnon and Ray, 1931; Ganapati, 1946; Kamm, 1922; Fowel, 1936; de Faria et al., 1918; Rueckert et al., 2018; Supplementary Material STable 3). No molecular sequence data are available for Polyrhabdina except for two sequences published in Rueckert et al. (2018), which are currently retracted from GenBank to clarify potential fungal contamination (Dr. Rueckert, personal communication).

In Polyrhabdina spp., the only life cycle stages that have ever been described are the trophozoite, usually with a globular AO embedded in the host epithelium, and the gamont that usually lost its AO during separation from the host tissue. In trophozoites, some authors observed hook-like processes on the apical AO surface in addition to a circlet of tiny prongs ("teeth") at its base (Caullery and Mesnil, 1914a; Ganapati, 1946; von Kölliker, 1848; Mackinnon and Ray, 1931; Reichenow, 1932; Rueckert et al., 2018). In contrast, others described the AO with a collar, a posteriorly oriented circular fold, at its base and sometimes with a ring of small prongs, anterior to the collar (Fowell, 1936; Léger, 1893; Mackinnon and Ray, 1931). There was no consensus in these works on calling the AO a mucron or epimerite (Supplementary Material STable 3).

Caullery and Mesnil recorded the eugregarine Polyrhabdina pygospionis in polychaetes Pygospio seticornis (now P. elegans) from the English Channel but did not provide an adequate description of this species. The host name and the infection caused by microsporidia Metchnikovella incurvata and $M$. oviformis are available evidence from this species (Caullery and Mesnil, 1914a, 1914b, 1919). We believe that we collected namely eugregarines $P$. pygospionis in the White Sea because they parasitized $P$. elegans polychaetes and were found to be infected by the microsporidium M. incurvata (Paskerova et al., 2016; Rotari et al., 2015; Sokolova et al., 2013 - in these articles, this gregarine is called Polyrhabdina sp.). Our transmission electron microscopic study of this eugregarine revealed peculiarities of the pellicle structure: the presence of loops of the internal lamina under epicytic grooves, which is not typical for eugregarines, and the absence of the internal lamina links at the epicytic crest bases, which is characteristic of some aseptate and septate eugregarines, e.g. Ancora and Stylocephalus (Desportes, 1969; Simdyanov, 1995; Simdyanov et al., 2017). Moreover, the AO of this gregarine is constructed as the epimerite of other studied eugregarines (see below). Based on the

Peer] reviewing PDF | (2020:12:56148:1:1:NEW 27 Jun 2021) 
457 light, scanning and transmission electron microscopic data obtained in this study, we amend the 458 diagnosis for $P$. pygospionis (see Taxonomic summary).

Eugregarines $P$. spionis and P. bifurcata (Mackinnon, Ray, 1931) Reichenow, 1932 were

460

461

462

463

464

465

466

467

468

469

470

471

472

473

474

475

476

477

478

479

480

481

482

483

484

485

486

487

488

489

490

491

492

493

494

495

496

497

498

499

500

501

502 isolated from the polychaete Scolelepis fuliginosa (Claparède, 1868) (now Malacoceros

fuliginosus). They were considered to be either variants of the same species $P$. spionis

(Mackinnon and Ray, 1931) or separate species (Reichenow, 1932) distinguished by the number and morphology of prongs on the AO surface (Supplementary Material STable 3). P. spionis has the epimerite with seven-nine bifurcated apical prongs, while P. bifurcata - with two large clawlike apical processes and a basal circlet of 14-16 minute prongs. According to previously published drawings, the gregarines that we isolated from the polychaetes Malacoceros fuliginosus were more similar to $P$. spionis in appearance. Presumably, we observed young trophozoites of $P$. spionis judging from their reported cell sizes (Caullery and Mesnil, 1914a; Mackinnon and Ray, 1931; Reichenow, 1932; Supplementary Material STable 3). Since we did not study the ultrastructure of Polyrhabdina cf. spionis, we cannot discuss the presence of prongs on the AO surface. Additionally, a collar at the AO base that we observed in P. pygospionis and P. cf. spionis has also been described in P. polydora (Caullery and Mesnil, 1914a; Kamm, 1922; Makkinnon and Ray, 1931; Fowell, 1936).

On the base of the superficial morphology of $P$. pygospionis and $P$. cf. spionis, the type species, and data on the fine structure of AO and cortex in P. pygospionis, we emend the diagnosis of the genus Polyrhabdina (see Taxonomy summary).

Kamm (1922) established the family Polyrhabdinidae for genera Polyrhabdina, Sycia Léger 1892, and Ulivina Mingazzini 1891 uniting septate eugregarines with the epimerite-type AO. The species composition of these genera is still not defined because their morphological characteristics are insufficient and overlapping. The only species, S. inopinata Léger 1891, has been investigated by transmission electron microscopy. Sycia spp. and Ulivina spp. occur mostly in the Cirratulidae and Eunicidae polychaetes (Desportes and Schrével, 2013; Schrével, 1969; Schrével and Vivier, 1966).

Similar to Polyrhabdina spp., an area of light, non-granulated cytoplasm in the cell under the AO was revealed in Sycia and Ulivina eugregarines by light microscopic studies. However, neither our electron microscopic data on Polyrhabdina pygospionis, nor the data on the fine structure of $S$. inopinata confirm the presence of a fibrillar septum dividing the gregarine cell into the anterior and nucleated posterior parts, as characteristic of true septate eugregarines (Desportes and Schrével, 2013; Ganapati, 1946; Kamm, 1922; Mingazinni, 1891; Schrével, 1969; Schrével and Vivier, 1966; present study).

In gregarines of these genera, AOs vary from a small papilla with or without a long filament at the apex in Ulivina spp. to a large rounded papilla with a thick collar ("ring") around the base in Sycia spp. The figures of S. inopinata in Schrével and Vivier (1966) and Schrével (1969), as well as personal communications of Prof. Schrével, allow suggesting that the collar is covered by the three-membrane pellicle and that the IMC terminates above the collar, but not under it as in P. pygospionis. Presumably, the collar of $S$. inopinata is a circular protrusion of the eugregarine cell under the globular AO. In addition, the granular cytoplasm with short fibrils in the AO base in P. pygospionis may correspond to a sphincter ring described in the AO in $S$. inopinata. In comparison with the pellicle of $P$. pygospionis, links of the internal lamina in the base of the epicytic crest as well as loops of the internal lamina under the bottom of epicytic grooves were apparently absent in S. inopinata (Desportes and Schrével, 2013; Schrével, 1969; Schrével and Vivier, 1966).

Peer) reviewing PDF | (2020:12:56148:1:1:NEW 27 Jun 2021) 
503

504

505

506

507

508

509

510

511

512

513

514

515

516

517

518

519

520

521

522

523

524

525

526

527

528

529

530

531

532

533

534

535

536

537

538

539

540

541

542

543

544

545

546

547

548

Due to scarce morphological and missing molecular data, the genera Sycia and Ulivina remain to be revised, and their relationships with Polyrhabdina need to be proved.

\section{Epimerite is a shared characteristic of eugregarines}

The fine structure of attachment organelles was investigated in archigregarines Selenidium spp., aseptate eugregarines Ancora sagittata, Difficilina cerebratuli, Lankesteria levinei, Lecudina spp., and septate gregarines Didymophyes gigantea, Epicavus araeoceri, Gregarina spp., Leidyana ephestiae, Pyxinia firmus, Stylocephalus africanus. A revision of these data (Simdyanov et al., 2017) revealed conspicuous differences between the attachment organelles of archigregarines and eugregarines and proposed to restrict the term "epimerite" to the AO in eugregarines, but the term "mucron" to the AO in archigregarines. The epimerite is an anchoring organelle, which varies in size and shape, and it is sometimes equipped with projections. It is usually embedded in the host cell invagination and bordered by a circular gap which runs around the AO base and pinches a small portion of the host cell. The epimerite is covered only by the plasma membrane, while the inner membrane complex (IMC) of the pellicle terminates close to the circular gap at the epimerite base. Between the epimerite and infected host cell, a kind of tight cell junction is apparently formed. It may facilitate feeding by transmembrane transport. In trophozoites during their transformation from the zoite, the epimerite originates as a new organelle in front of their anterior end, with the simultaneous disappearance of some organelles of the apical complex characteristic of the zoite. As trophozoites develop into gamonts and detach from the host cell, they can lose the epimerite. In contrast, the mucron is usually small, rounded or sucker-shaped. It represents the hypertrophic developed anterior end of the zoite and performs feeding by using its well-developed apical complex as a cytostome-cytopharyngeal gateway for the myzocytosis - the feeding by sucking. The mucron persists in trophozoites and gamonts, and even at the syzygy stage. The recently obtained results on the fine structure of blastogregarines are in good agreement with the proposed hypothesis: blastogregarines, which share some plesiomorphic characters of archigregarines, possess the AO of similar structure and function of the mucron (Simdyanov et al. 2018).

According to our results, the AO of two Polyrhabdina spp. is organized in the same way as epimerites of other previously studied aseptate and septate eugregarines (Fig. 7). It represents an anchoring organelle covered only by the plasma membrane forming a kind of tight cell junction with the host cell membrane, and can be lost in gamonts. The evidence obtained in this study strongly corroborates the suggestion, that the epimerite is a shared, derived character (synapomorphy) of all eugregarines, both septate and aseptate, while the mucron is an intrinsic feature of archigregarines and blastogregarines - sporozoans preserving the apicomplexan zoite structure at the trophozoite and gamont stages (Simdyanov et al., 2017, 2018). This revised view on AO homology is in agreement with the recently emended diagnosis of Eugregarinida (Simdyanov et al., 2017).

\section{The resurrected family Polyrhabdinidae and the emended superfamily Ancoroidea} Molecular phylogenetic analyses of ribosomal RNA genes (SSU, 5.8S, and LSU rDNA) show that $P$. pygospionis typifies a large lineage of environmental eukaryotic sequences from marine sediments, which was previously shown to be related to Ancoroidea and designated as incertae sedis among gregarines (Simdyanov et al., 2017). Additionally, the recent protein multigene phylogeny also revealed the affiliation of P. pygospionis (Polyrhabdina sp. in original) with Ancoroidea (Janouškovec et al., 2019; Mathur et al., 2021). We conclude that the clade including

Peer] reviewing PDF | (2020:12:56148:1:1:NEW 27 Jun 2021) 
549 P. pygospionis can be identified as the family Polyrhabdinidae Kamm, 1922, a taxon that should 550 be re-established with a diagnosis emended by new morphological evidence (see Taxonomic 551 summary). The two subclades identified in our phylogenetic analysis in the clade

552 Polyrhabdinidae may correspond to Polyrhabdina, Sycia and/or Ulivina genera, but this needs to 553 be further investigated.

554 Geographical mapping of the polyrhabdinid environmental samples reveals their 555 worldwide distribution: deep sea sediment from the East Sea (Park et al., 2008), sediment from 556 seashores of Denmark (Karst et al., 2018), sediment of mangrove system in Brazil (Santos et al., 557 2010), methane cold seep in Sagami Bay in Japan, the tidal flat on Disko Island near Greenland, 558 Cariaco basin in the Caribbean Sea near Venezuela, marine stromatolites near the Bahamas 559 (Baumgartner et al., 2009; Stoeck et al., 2003, 2007; Takishita et al., 2007), and a clone derived 560 from the foraminiferan Ammonia beccarii (Wray et al., 1995). The identification of the latter sequence as a foraminiferan was refuted (Pawlowski et al., 1996), and it probably originated by either pseudoparasitism, occasional ingestion of a gregarine oocysts by the foraminiferan (see Rueckert et al. (2011) for similar cases of misidentification).

SSU + LSU rDNA phylogeny, SSU rDNA phylogenies built with alternative alignment procedures, and the BI analysis performed in PhyloBayes confirm the placement of Trollidium akkeshiense within the Ancoroidea. In addition, most Trollidium, Polyrhabdinidae, and related environmental sequences share an unusual feature in the predicted secondary structure of helix 17 of the SSU rRNA that might indicate their common ancestry. Earlier, helix 17 was identified as a phylogenetic marker of some metazoan and protistan clades (Aleshin et al, 1998; Nikolaev et al., 2004). The clade associated with T. akkeshiense and several related environmental sequences was previously assigned to the family Lecudinidae (Rueckert and Leander, 2010; Rueckert et al., 2013; Wakeman, 2020). Following the criteria established in earlier taxonomic revisions of gregarines based on rDNA phylogenies (Clopton, 2009; Cavalier-Smith, 2014; Paskerova et al., 2018; Simdyanov et al., 2017), we erect the SSU rDNA clade, typified by $T$. akkeshiense, as a new family Trollidiidae (see Taxonomic summary). GUIDANCE2 alignment tends to place the Trichotokara+Paralecudina clade in the Ancoroidea, while the manually masked alignment brings these groups closer together only if using a BI under the CAT model (PhyloBayes tree), which is most free from the artifact of long branch attraction, or if excluding the most divergent sequences from the alignment (65 OUT tree). This is consistent with a recent multigene analysis of Trichotokara as a sister group to Ancoroidea (Mathur et al., 2021). Generally, the GUIDANCE2 strategy showed less stable results than the structural alignment utilizing the X-INS-i algorithm, in particular with regard to placement of the Trichotokara and Paralecudina clade as well as the Cephaloidophora and Trollidiidae clades. The PCA result also showed that fully manual constructed alignments gave more stable results than the other two automatic alignments. The rDNA data offers method-dependent resolution for the composition of the Ancoroidea, and the results require further refinement. Currently, we propose that the superfamily Ancoroidea combines four families: Ancoridae Simdyanov et al., 2017, Polyplicariidae Cavalier-Smith, 2014, Polyrhabdinidae Kamm, 1922, emend., and Trollidiidae fam. nov. Characteristics of these groups are given in Taxonomic summary.

\section{Candidate synapomorphies of the family Polyrhabdinidae and the emended superfamily Ancoroidea}


593 Comparative analysis of the ultrastructural data and reconciling those with the molecular 594 phylogenies allow us to detect additional candidate synapomorphies of Polyrhabdinidae and 595 Ancoroidea.

In the attached eugregarines $P$. pygospionis and $P$. cf. spionis, almost the whole epimerite is embedded into the host cell, except for the collar, which is located above the surface of the host cell. The collar appears to be a shared characteristic of the genus Polyrhabdina and possibly also of the family Polyrhabdinidae, provided that the relationship of Sycia with this family is confirmed. The epimerite and its collar may provide a scaffold for formation of projections and prongs for better attachment to the host cell.

A shared characteristic among many gregarines that make up the clade Ancoroidea is a well-developed protruded epimerite detected in Ancora (family Ancoridae Simdyanov et al., 2017), Polyplicarium (Polyplicariidae Cavalier-Smith, 2014), Polyrhabdina (Polyrhabdinidae Kamm, 1922, emend.) (Cavalier-Smith, 2014; Cecconi, 1905; Simdyanov et al., 2017; Wakeman and Leander, 2013; this study). The epimerite is usually lost in parasites detached from the host cell. In place of the lost epimerite (discarded or retracted), a residual structure may be retained, e.g., a disk-shaped protrusion ("mucron" in original) observed in Trollidium akkeshiense (Wakeman, 2020).

Another shared characteristic and a candidate synapomorphy of the superfamily Ancoroidea is likely the absence of the links of the internal lamina in between the bases of the epicytic crests (Fig. 2I). Apart from P. pygospionis, the links are absent in Ancora sagittata (Simdyanov et al., 2017) and, re-examining pictures in the original studies, most likely also in Trollidium akkeshiense (Wakeman, 2020: Fig. 12), and in Sycia inopinata (Schrével, 1969: Fig. 23), a presumable member of the superfamily. Septate gregarines of the genus Stylocephalus (Desportes, 1969; Desportes and Schrével, 2013) also lack the links but are not related to Ancoroidea (Fig. 5), indicating that the two taxa acquired similar epicyte structure by convergent loss of the internal lamina links.

It is possible that the superfamily Ancoroidea includes other known species of marine gregarines. The eugregarines Kamptocephalus mobilis Simdyanov, 1995 and Mastigorhynchus bradae Simdyanov, 1995, parasitizing flabelligerid polychaetes, resemble T. akkeshiense by the fine structure of the epicyte and by the type of motility (Simdyanov, 1995; Wakeman, 2020). All these gregarines have wide epicytic crest without links of the internal lamina in their base and possess a well-developed epimerite, which is usually absent in gamonts. In addition, K. mobilis shows both intermittent bending of the anterior third of the body and fast gliding, and has a massive bundle of longitudinal microtubules in the subpellicular cytoplasm (Simdyanov, 1995). Hence, K. mobilis and M. bradae have all the features of Trollidium and ancoroids in general, but their affiliation is yet to be confirmed by molecular analyses.

\section{Notes on gregarine co-parasitism and microsporidian hyperparasitism in polychaetes}

Eugregarines Polyrhabdina species often co-occur with archigregarines Selenidium species in the same polychaete host (Supplementary Material STable 3). Our observations suggest that in coinfection of P. pygospionis and S. pygospionis in Pygospio elegans (Paskerova et al., 2018; this study) each parasite species is more abundant than in monoinfections. Eugregarines, blastogregarines, and archigregarines regularly harbour metchnikovellid microsporidia (Caullery and Mesnil, 1897a, b, 1914b, 1919 ; Ganapati, 1946; Mackinnon and Ray, 1931; Mikhailov et al., 2021; Paskerova et al., 2016, 2018; Rotari et al., 2015; Sokolova et al., 2013, 2014; Supplementary Material STable 3). Further studies focused on metchnikovellids that infect 
639 gregarines co-occurring in the same spionid polychaete may shed some light on the

640 diversification of metchnikovellids and co-evolution of gregarine hosts and their hyperparasitic

641 microsporidia.

642

643

644

645

646

647

648

Taxonomic summary

Phylum Apicomplexa Levine, 1970

Subphylum Sporozoa Leuckart, 1879

Class Gregarinomorpha Grassé, 1953, emend. Simdyanov et al., 2017

Order Eugregarinida Léger, 1900, emend. Simdyanov et al., 2017.

Superfamily Ancoroidea Simdyanov et al., 2017, emend.

650

Diagnosis. Eugregarinida. Typically aseptate; trophozoites typically with prominent epimerite; epimerite lost in gamonts; micropores on lateral walls of epicytic crests lacking the links of the

651

652 Type family. Ancoridae Simdyanov et al., 2017. internal lamina in their bases. In polychaetes, intestine.

653

654

Remarks. Four families. The superfamily may be supplemented with parasites of Flabelligeridae

655 polychaetes, Kamptocephalus mobilis Simdyanov, 1995, Mastigorhynchus bradae Simdyanov,

656 1995, which share the characteristics of the epicyte structure and motility with those of ancoroids

657 (see Discussion). The affiliation of these gregarines with this superfamily needs to be tested.

657 Family Polyrhabdinidae Kamm, 1922, emend.

658

659

Diagnosis. Ancoroidea. Trophozoites and gamonts ovoid, aseptate; epimerite massive, with

660 various appendages: prongs and/or basal collar (posteriorly oriented circular fold at the epimerite base). Intestine of polychaetes.

661 Type genus. Polyrhabdina Mingazzini, 1891.

662 Remarks. One to three genera. Sycia and Ulivina species have non-granulated cytoplasm in the cell body under the epimerite, which gives their appearance of septate cells. The validity and

665 composition of these genera and its close relations to Polyrhabdina and other ancoroid eugregarines must be clarified.

666 Genus Polyrhabdina Mingazzini, 1891, emend.

667 Diagnosis. Polyrhabdinidae. Trophozoites and gamonts aseptate. Intestine of Spionidae.

668 Type species. Polyrhabdina spionis (Kölliker, 1848) Mingazinni, 1891.

669 Remarks. Seven named species.

670 Polyrhabdina pygospionis Caullery and Mesnil, 1914, emend.

671 Original description. Polyrhabdina pygospionis, n. sp., from Pygospio seticornis (now $P$.

672 elegans) (Caullery and Mesnil 1914a). Infected by microsporidia Metchnikovella incurvata

673 Caullery et Mesnil, 1914 and M. oviformis Caullery et Mesnil, 1914 (Caullery and Mesnil 1914b,

674 1919). Gregarines generally abundant in the polychaete intestine, similar to P. brasili Caullery et

675 Mesnil, 1914 from Spio martinensis Mesnil, 1896 but smaller (Caullery and Mesnil, 1919).

676 Re-description (amended diagnosis). Characteristics of the genus. Trophozoites and gamonts

677 ellipsoid (sometimes slightly curved) to pear-shaped, circular in cross section, 28-288 x 14-50

$678 \mu \mathrm{m}$. Nucleus oval to spherical, 9.5-19.0 x 9.5-17.0 $\mu \mathrm{m}$, oriented longitudinally in the widest part 679 of the cell, with single large or 2-3 small nucleoli of various localisation. Epimerite domed, 3.7$6804.9 \mu \mathrm{m}$ in base diameter, with a posteriorly oriented circular fold (collar), 0.2-1.7 $\mu \mathrm{m}$ tall, and an 681 annular narrow and deep gap at the base; lost (presumably discarded) in gamonts of different 682 sizes. Epicytic crests (about 5/ $\mu \mathrm{m}$ ) with 10-12 apical rippled dense structures and 10-12 apical 683 filaments in the tops. Other stages not found. Infected by different metchnikovellidean 684 microsporidia. 
685 Type locality. Anse Saint-Martin, English Channel, North East Atlantic.

686 Type definitive host. Pygospio elegans (former P. seticornis) Claparède, 1863 (Polychaeta, 687 Spionidae).

688 Locality and host used in amended diagnosis. Kandalaksha Bay, White Sea; Pygospio elegans

689 Claparède, 1863 (Polychaeta, Spionidae).

690 Ecology/Habitat. Marine.

691 Type materials. Lost.

692 Deposition of specimens and materials used in amended diagnosis. Resin blocks and fixed

693 slides containing eugregarines and pieces of infected host intestine deposited in the collection of

694 Department of Invertebrate Zoology, St Petersburg State University; Figures 1-3 (this

695 publication) show some of these specimens (White Sea). DNA sequences: contiguous sequence

696 of SSU, ITS1, 5.8S, ITS2, and LSU rDNA from the individuals, isolated from the polychaetes

697 Pygospio elegans (Kandalaksha Bay, White Sea) (GenBank accession number MT214481).

698 Family Trollidiidae fam. nov.

699 Diagnosis. Ancoroidea. Free individuals (putatively gamonts; epimerite unknown) with

700 extraordinarily wide longitudinal epicytic crests, some crests zigzag; the network of longitudinal

701 microtubules in cortex under the zigzag epicytic crests; bending/twitching motility. Intestine of

702 Flabelligeridae. Monotypic.

703 Type genus. Trollidium Wakeman, 2020.

704 ZooBank Registration: LSID urn:lsid:zoobank.org:pub:693369E6-B319-4BB1-8E61-

705 148FC4F5B271. ZooBank Nomenclature Act: LSID urn:1sid:zoobank.org:act:239658AC-

706 6AE9-4641-B2F3-E18FE5616363.

707 Remarks. The family may be supplemented with other parasites of Flabelligeridae polychaetes,

708 Kamptocephalus mobilis Simdyanov, 1995 and Mastigorhynchus bradae Simdyanov, 1995,

709 which share with Trollidium the characteristics of the epicyte structure and motility (see

710 Discussion). The affiliation of these gregarines with this family needs to be tested.

711

712

\section{Conclusions}

713 On the base of comprehensive study, we re-described the aseptate eugregarine Polyrhabdina

714 pygospionis Caullery, Mesnil, 1914 from the polychaete Pygospio elegans, collected in the

715 White Sea. We also demonstrated that the attachment organelles of $P$. pygospionis and $P$. cf.

716 spionis, the type species, represented the epimerite in its organization. This evidence once again

717 proves that the epimerite is an innovation of eugregarines. The phylogenetic analyses using

718 concatenated ribosomal operon DNA sequences revealed that $P$. pygospionis was not related to

719 lecudinoid eugregarines (the superfamily Lecudinoidea Simdyanov et al., 2017), but to ancoroid

720 eugregarines (the superfamily Ancoroidea Simdyanov et al., 2017). Based on the results of

721 ribosomal phylogenetic analysis and comparative analysis of the literature data, we revised the

722 superfamily Ancoroidea and proposed the following synapomorphies for this group: the well-

723 developed protruded epimerite usually missing in gregarines detached from the host cell and the

724 absence of the links of the internal lamina joining the base of the epicytic crests. Accordingly,

725 the superfamily unites four families: Ancoridae Simdyanov et al., 2017, Polyplicariidae Cavalier-

726 Smith, 2014, Polyrhabdinidae Kamm, 1922, emend., and Trollidiidae fam. nov.

727

728

729

\section{Acknowledgments}

730 University, the White Sea Biological Station of Moscow State University for providing facilities 
731 for field sampling and material processing. GGP is grateful to Professor Rudolf Entzeroth and

732 Markus Gunther (Technical University of Dresden) for providing facilities for her research. GGP

733 and TSM utilized equipment of the core facility centers of St Petersburg State University:

734 "Molecular and Cell Technologies" for electron microscopy and "Observatory of Environmental

735 Safety" for culturing of marine invertebrates. AV and MK are grateful to the Laboratory of

736 Electron Microscopy, Biology Centre CAS, an institution supported by the Czech-BioImaging

737 large RI project (LM2015062 funded by MEYS CR), for their help with obtaining some EM

738 data. TGS utilized equipment of the Electron Microscopy Laboratory of the Faculty of Biology

739 and the Center of Microscopy of the White Sea Biological Station, Lomonosov Moscow State

740 University. The research was carried out as part of the scientific project of the state order of the

741 government of Russian Federation to Lomonosov Moscow State University No.121032300117-

7423.

743

744

745

746

747

748

749

750

751

752

753

754

755

756

757

758

759

760

761

762

763

764

765

766

767

768

769

770

771

772

773

774

\section{References}

Adl SM, Bass D, Lane CE, Lukeš J, Schoch CL, Smirnov A, Agatha S, Berney C, Brown MW, Burki F, Cárdenas P. 2019. Revisions to the classification, nomenclature, and diversity of eukaryotes. J. Eukaryot. Microbiol. 66(1), 4-119.

Aleshin VV, Kedrova OS, Milyutina IA, Vladychenskaya NS, Petrov NB. 1998. Secondary structure of some elements of 18S rRNA suggests that strongylid and a part of rhabditid nematodes are monophyletic. FEBS Letters 429, 4-8.

Altschul SF, Madden TL, Schäffer AA, Zhang J, Zhang Z, Miller W, Lipman DJ. 1997. Gapped BLAST and PSI-BLAST: a new generation of protein database search programs. Nucleic Acids Res. 25(17), 3389-3402.

Baumgartner LK, Spear JR, Buckley DH, Pace NR, Reid RP, Dupraz C, Visscher PT. 2009. Microbial diversity in modern marine stromatolites, Highborne Cay, Bahamas. Environ. Microbiol. 11(10), 2710-2719.

Capella-Gutierrez S, Silla-Martinez JM, Gabaldon T 2009. trimAl: a tool for automated alignment trimming in large-scale phylogenetic analyses. Bioinformatics 25: 1972-1973. doi: 10.1093/bioinformatics/btp348

Caullery M, Mesnil F. 1897a. Sur un type nouveau (Metchnikovella n.g.) d'organismes parasites des grégarines. C. R. Soc. Biol. 49, 960-962.

Caullery M, Mesnil F. 1897b. Sur trois sporozoaires parasites de la Capitella capitata O.Fab. C. R. Soc. Biol. 49, 1005-1008.

Caullery M, Mesnil F. 1914a. Sur l'existence de grégarines dicystidées chez les annélides polychètes. C. R. Soc. Biol. 77, 516-520.

Caullery M, Mesnil F. 1914b. Sur les Metchnikovellidae et autres protistes parasites des grégarines d'annélides. C. R. Soc. Biol. 77, 527-532.

Caullery M, Mesnil F. 1919. Metschnikovellidae et autres protistes parasites des Gregarines d' Annelides. Ann. Inst. Pasteur 33(4), 209-240.

Cavalier-Smith T. 2014. Gregarine site-heterogeneous 18S rDNA trees, revision of gregarine higher classification, and the evolutionary diversification of Sporozoa. Eur. J. Protistol. 50(5), 472-495.

Cecconi J. 1905. Sur l'Anchorina sagittata Leuck., parasite de la Capitella capitata O. Fabr. Arch. Protistenkunde. 6, 230-244. 
Clopton RE. 2009. Phylogenetic Relationships, Evolution, and Systematic Revision of the Septate Gregarines (Apicomplexa: Eugregarinorida: Septatorina). Comp. Parasitol. 76(2), 167-190.

Clopton R. 2000. Order Eugregarinorida Léger, 1900. In: Lee JJ, Leedale GF, Bradbury F. (eds.). An illustrated guide to the protozoa: organisms traditionally referred to as protozoa, or newly discovered groups. Lawrence: Society of Protozoologists. 1, 205-298.

de Faria G, de Cunha M, da Fonseca OR. 1918. Protozoarios parazitos de "Polydora socialis". Mem. Inst. Osw-Cruz. 10, 17-19.

Desportes I. 1969. Ultrastructure et développement des Grégarines du genre Stylocephalus. Ann. sci. nat., Zool. biol. anim. 11, 31-96.

Desportes I, Schrével J. (eds.). 2013. Treatise on Zoology-Anatomy, Taxonomy, Biology. The Gregarines (2 vols). The early branching Apicomplexa. Brill Leiden, Boston.

Diakin A, Paskerova GG, Simdyanov TG, Aleoshin VV, Valigurová A. 2016. Morphology and molecular phylogeny of coelomic gregarines (Apicomplexa) with different types of motility: Urospora ovalis and U. travisiae from the polychaete Travisia forbesii. Protist. 167, 279-301.

Edgar RC. 2004. MUSCLE: multiple sequence alignment with high accuracy and high throughput. Nucleic Acids Res. 35,1792-1797.

Fowell RR. 1936. Observations on the Sporozoa inhabiting the gut of the polychaete worm Polydora flava Claparède. Parasitology. 28, 414-430;

Ganapati, P.N., 1946. Notes on some gregarines from polychaetes of the Madras coast. Proc. Ind. Acad. Sci. Sect.B. 23(5), 228-248.

Grassé PP. 1953. Classe des gregarinomorphes (Gregarinomorpha n. nov.; Gregarinae Haeckel, 1866; Gregarinidea Lankester, 1885; gregarines des auteurs). Paris, Masson \& Cie. 1, 550-690.

Hall TA. 1999. BioEdit: a user-friendly biological sequence alignment editor and analysis program for Windows 95/98/NT. Nucleic Acids Symp. Ser. 41, 95-98.

Jamy M, Foster R, Barbera P, Czech L, Kozlov A, Stamatakis A, Bending G, Hilton S, Bass D, Burki F. 2019. Long-read metabarcoding of the eukaryotic rDNA operon to phylogenetically and taxonomically resolve environmental diversity. Mol. Ecol. Resour. 20(2), 429-443.

Janouškovec J, Paskerova GG, Miroliubova TS, Mikhailov KV, Birley T, Aleoshin VV, Simdyanov TG. 2019. Apicomplexan-like parasites are polyphyletic and widely but selectively dependent on cryptic plastid organelles. eLife, 8, e49662.

Kalyaanamoorthy S, Minh BQ, Wong TKF, von Haeseler A, Jermiin LS. 2017. ModelFinder: fast model selection for accurate phylogenetic estimates. Nature Methods 14, 587-589.

Kamm Watson M. 1922. Studies on gregarinies II. Synopsis of the polycystid gregarines of the world, excluding those from the Myriapoda, Orthoptera, and Coleoptera. Illinois Biological Monographs. VII(1), 1-103.

Karst S, Dueholm M, McIlroy S, Kirkegaard RH, Nielsen PH, Albertsen M. 2018. Retrieval of a million high-quality, full-length microbial $16 \mathrm{~S}$ and $18 \mathrm{~S}$ rRNA gene sequences without primer bias. Nat. Biotechnol. 36(2), 190-195.

Katoh K, Standley DM. 2013. MAFFT Multiple Sequence Alignment Software Version 7: Improvements in Performance and Usability. Molecular Biology and Evolution 30, 772 780 . 
820

821

822

823

824

825

826

827

828

829

830

831

832

833

834

835

836

837

838

839

840

841

842

843

844

845

846

847

848

849

850

851

852

853

854

855

856

857

858

859

860

861

862

863

864

865

Landan G, Graur D. 2008. Local reliability measures from sets of co-optimal multiple sequence alignments. Pacific Symposium on Biocomputing 13, 15-24.

Lartillot N, Rodrigue N, Stubbs D, Richer J. 2013. PhyloBayes MPI: phylogenetic reconstruction with infinite mixtures of profiles in a parallel environment. Systematic Biology 62, 611615.

Lê S, Josse J, Husson F. 2008. FactoMineR: An R package for multivariate analysis. Journal of Statistical Software 25, 1-18.

Léger L. 1893. L'evolution des gregarines intestinales des vers marins. C. R. Acad. Sci. 116, 204-206.

Levine ND. 1971. Uniform terminology for the protozoan subphylum Apicomplexa. J. Protozool. 18(2), 352-355.

Levine ND. 1977. Revision and checklist of the species (other than Lecudina) of the aseptate gregarine family Lecudinidae. J. Protozool. 24(1), 41-52.

Lewis PO, Holder MT, Swofford DL. 2015. Phycas: software for Bayesian phylogenetic analysis. Systematic Biology 64, 525-531.

Mackinnon DL, Ray HN. 1931. Observations on dicystid gregarines from marine worms. Quarterly Journal of Microscopical Science 74: 439-466.

Mathur V, Wakeman K, Keeling P. 2021. Parallel functional reduction in the mitochondria of apicomplexan parasites. Current Biology (in press), https://doi.org/10.1016/j.cub.2021.04.028

Mikhailov KV, Nassonova ES, Shishkin YA, Paskerova GG, Simdyanov TG, Yudina VA, Smirnov AV, Janou $\square$ kovec J, Aleoshin VV. 2021. Ribosomal RNA of the metchnikovellids in gregarine transcriptomes and rDNA of the microsporidia sensu lato in environmental metagenomes. Zhurnal Obshchei Biologii 82 (3), 201-228 (in Russian with English Summary).

Miller MA, Pfeiffer W, Schwartz T. 2010. Creating the CIPRES Science Gateway for inference of large phylogenetic trees. In: Gateway Computing Environments Workshop (GCE). New Orleans, LA. 1-8.

Mingazzini P. 1891. Gregarine monocistidee, nuove o poco conosiute, del Golfo di Napoli. Atti Reale Accad. Lincei. Rendiconti. 7, 229-235.

Minh BQ, Nguyen MAT, von Haeseler A. 2013. Ultrafast Approximation for Phylogenetic Bootstrap. Molecular Biology and Evolution 30, 1188-1195.

Minh BQ, Schmidt HA, Chernomor O, Schrempf D, Woodhams MD, von Haeseler A, Lanfear R. 2020. IQ-TREE 2: New Models and Efficient Methods for Phylogenetic Inference in the Genomic Era. Molecular Biology and Evolution 37, 1530-1534.

Nikolaev SI, Mylnikov AP, Berney C, Fahrni J, Pawlowski J, Aleshin VV, Petrov NB. 2004. Molecular phylogenetic analysis places Percolomonas cosmopolitus within Heterolobosea: evolutionary implications. Journal of Eukaryotic Microbiology 51, 575581.

Park SJ, Park BJ, Pham VH, Yoon DN, Kim SK, Rhee SK. 2008. Microeukaryotic diversity in marine environments, an analysis of surface layer sediments from the East Sea. J. Microbiol. 46(3), 244-249.

Paskerova GG, Frolova EV, Kováčiková M, Panfilkina TS, Mesentsev ES, Smirnov AV, Nassonova ES. 2016. Metchnikovella dogieli sp. n. (Microsporidia: Metchnikovellida), a parasite of archigregarines Selenidium sp. from polychaetes Pygospio elegans. Protistology. 10, 148-157. 
866

867

868

869

870

871

872

873

874

875

876

877

878

879

880

881

882

883

884

885

886

887

888

889

890

891

892

893

894

895

896

897

898

899

900

901

902

903

904

905

906

907

908

909

910

Paskerova GG, Miroliubova TS, Diakin A, Kováčiková M, Valigurová A, Guillou L, Aleoshin VV, Simdyanov TG. 2018. Fine structure and molecular phylogenetic position of two marine gregarines, Selenidium pygospionis sp. n. and S. pherusae sp. n., with notes on the phylogeny of Archigregarinida (Apicomplexa). Protist. 169, 826-852.

Pawlowski J, Bolivar I, Fahrni JF, Cavalier-Smith T, Gouy M. 1996. Early origin of foraminifera suggested by SSU rRNA gene sequences. Mol. Biol. Evol. 13, 445-450.

Penn O, Privman E, Ashkenazy H, Landan G, Graur D., Pupko T. 2010. GUIDANCE: a web server for assessing alignment confidence scores. Nucleic Acids Research 38, W23-W28.

R Core Team. 2021. R: A language and environment for statistical computing. R Foundation for Statistical Computing, Vienna, Austria. https://www.R-project.org/

Reichenow E. 1929. Sporozoa. In: Doflein F, Reichenow R. (eds.). Lehrbuch der Protozoenkunde: eine Darstellung der Naturgeschichte der Protozoen mit besonderer Berücksichtigung der parasitischen und pathogenen Formen. Jena, Fünfte Auflage. Teil II, 863-1153.

Reichenow E. 1932. Sporozoa. In: Grimpe G, Wagler E. (eds). Die Tierwelt der Nord und Ostsee. Leipzig. Lief 21 (Teil II), 1-88.

Ronquist F, Teslenko M, van der Mark P, Ayres DL, Darling A, Höhna S, Larget B, Liu L, Suchard MA, Huelsenbeck JP. 2012. MrBayes 3.2: efficient Bayesian phylogenetic inference and model choice across a large model space. Syst. Biol. 61(3), 539-342.

Rotari YM, Paskerova GG, Sokolova YY. 2015. Diversity of metchnikovellids (Metchnikovellidae, Rudimicrosporea), hyperparasites of bristle worms (Annelida, Polychaeta) from the White Sea. Protistology. 9, 50-59.

Rueckert S, Glasinovich N, Diez ME, Cremonte F, Vázquez N. 2018. Morphology and molecular systematic of marine gregarines (Apicomplexa) from Southwestern Atlantic spionid polychaetes. J. Invertebr. Pathol. 159, 49-60.

Rueckert S, Leander BS. 2010. Description of Trichotokara nothriae n. gen. et sp. (Apicomplexa, Lecudinidae) - an intestinal gregarine of Nothria conchylega (Polychaeta, Onuphidae). J. Invertebr. Pathol. 104, 172-179.

Rueckert S, Simdyanov TG, Aleoshin VV, Leander BS. 2011. Identification of a divergent environmental DNA sequence clade using the phylogeny of gregarine parasites (Apicomplexa) from crustacean hosts. PLoS ONE. 6, e18163.

Rueckert S, Wakeman KC, Leander BS. 2013. Discovery of a diverse clade of gregarine Apicomplexans (Apicomplexa: Eugregarinorida) from Pacific eunicid and onuphid polychaetes, including descriptions of Paralecudina n. gen., Trichotokara japonica n. sp., and T. eunicae n. sp. J. Eukaryot. Microbiol. 60, 121-136.

Santos HF, Cury JC, Carmo FL, Rosado AS, Peixoto RS. 2010. 18S rDNA sequences from microeukaryotes reveal oil indicators in mangrove sediment. PLoS One. 5(8), e12437.

Schrével J. 1969. Biologie, cytologie, physiologie des Grégarines parasites d'Annélides polychétes. Faculté des Sciences de Lille. Lille, Université de Lille. Thèse doctorat. CNRS AO 2570.

Schrével J,Vivier E. 1966. Etude de l' ultrastructurale et du role de la région antérieure (mucron et épimérite) de Grégarines parasites d' Annélides Polychètes. Protistologica. 2(3), 17-28.

Sela I, Ashkenazy H, Katoh K, Pupko T. 2015. GUIDANCE2: accurate detection of unreliable alignment regions accounting for the uncertainty of multiple parameters. Nucleic Acids Research 43, W7-W14.

Peer) reviewing PDF | (2020:12:56148:1:1:NEW 27 Jun 2021) 
911

912

913

914

915

916

917

918

919

920

921

922

923

924

925

926

927

928

929

930

931

932

933

934

935

936

937

938

939

940

941

942

943

944

945

946

947

948

949

950

951

952

953

954

Simdyanov TG. 1995. Two new species of gregarines with the aberrant structure of epicyte from the White Sea. Parazitologiya. 29, 305-315 (in Russian with English summary).

Simdyanov TG. 2007. Class Gregarinea Dufour, 1828. In: Protista: Handbook on zoology. St. Petersburg, Nauka. Pt. 2, 20-148 (in Russian with English summary).

Simdyanov TG, Diakin AY, Aleoshin VV. 2015. Ultrastructure and 28S rDNA phylogeny of two gregarines: Cephaloidophora cf. communis and Heliospora cf. longissima with remarks on gregarine morphology and phylogenetic analysis. Acta Protozool. 54, 241-263.

Simdyanov TG, Guillou L, Diakin AY, Mikhailov KV, Schréve, J, Aleoshin VV. 2017. A new view on the morphology and phylogeny of eugregarines suggested by the evidence from the gregarine Ancora sagittata (Leuckart, 1860) Labbé, 1899 (Apicomplexa: Eugregarinida). PeerJ. 5, e3354.

Simdyanov TG, Paskerova GG, Valigurová A, Diakin A, Kováčiková M, Schrével J, Guillou L, Dobrovolskij AA, Aleoshin VV. 2018. First ultrastructural and molecular phylogenetic evidence from the blastogregarines, an early branching lineage of plesiomorphic Apicomplexa. Protist. 169(5), 697-726.

Sokolova YY, Paskerova GG, Rotari YM, Nassonova ES, Smirnov AV. 2013. Fine structure of Metchnikovella incurvata Caullery and Mesnil 1914 (microsporidia), a hyperparasite of gregarines Polyrhabdina sp. from the polychaete Pygospio elegans. Parasitology. 140, 855-867.

Sokolova YY, Paskerova GG, Rotari YM, Nassonova ES, Smirnov AV. 2014. Description of Metchnikovella spiralis sp. n. (Microsporidia: Metchnikovellidae), with notes on the ultrastructure of metchnikovellids. Parasitology. 141, 1108-1122.

Stoeck T, Kasper J, Bunge J, Leslin C, Ilyin V, Epstein S. 2007. Protistan diversity in the Arctic: a case of paleoclimate shaping modern biodiversity? PLoS ONE. 2, e728.

Stoeck, T., Taylor, G.T., Epstein, S.S., 2003. Novel eukaryotes from the permanently anoxic Cariaco Basin (Caribbean Sea). Appl. Environ. Microbiol. 69, 5656-5663.

Tabei Y, Kiryu H, Kin T, Asai K 2008. A fast structural multiple alignment method for long RNA sequences. BMC Bioinformatics. 9(33). doi: 10.1186/1471-2105-9-33

Takishita K, Yubuki N, Kakizoe N, Inagaki Y, Maruyama T. 2007. Diversity of microbial eukaryotes in sediment at a deep-sea methane cold seep: surveys of ribosomal DNA libraries from raw sediment samples and two enrichment cultures. Extremophiles. 11, 563-576.

von Kölliker A., 1845. Die Lehre von der thierischen Zelle und den einfacheren thierischen Formelementen, nach den neuesten Fortschritten dargestellt. Zeitschrift für wissenschaftliche Botanik. 1(2), 46-102.

von Kölliker A. 1848. Beiträge zur Kenntniss niederer Thiere. Zeitschrift für wissenschaftliche Zoologie. 1, 1-37.

Wakeman KC, Leander BS. 2013. Identity of environmental DNA sequences using descriptions of four novel marine gregarine parasites, Polyplicarium n. gen.(Apicomplexa), from capitellid polychaetes. Mar. Biodivers. 43(2), 133-147.

Wakeman KC, Yabuki A, Fujikura K, Tomikawa K, Horiguchi T. 2017. Molecular phylogeny and surface morphology of Thiriotia hyperdolphinae n. sp. and Cephaloidophora oradareae n. sp. (Gregarinasina, Apicomplexa) isolated from a deep sea Oradarea sp. (Amphipoda) in the West Pacific. Journal of Eukaryotic Microbiology. 65(3), 372-381. 
955

956

957

958

959

960

961

962

963

964

965

966

967

968

969

970

971

972

973

974

975

976

977

978

979

980

981

982

983

984

985

986

987

988

989

990

991

992

993

994

995

996

997

998

999

Wakeman KC. 2020. Molecular phylogeny of marine gregarines (Apicomplexa) from the Sea of Japan and the Northwest Pacific including the description of three novel species of Selenidium and Trollidium akkeshiense n. gen. n. sp. Protist. 171, 125710.

Wickham H. 2016. ggplot2: Elegant Graphics for Data Analysis: Springer-Verlag New York.

Wray CG, Langer MR, DeSalle R, Lee JJ, Lipps JH. 1995. Origin of the foraminifera. Proc. Natl. Acad. Sci. U S A. 92(7), 141-145.

Wuyts J, Van de Peer Y, De Wachter R. 2001. Distribution of substitution rates and location of insertion sites in the tertiary structure of ribosomal RNA. Nucleic Acids Research 29, 5017-5028.

Zuker M. 2003. Mfold web server for nucleic acid folding and hybridization prediction // Nucleic Acids Res. 31(13), 3406-3415.

\section{FIGURE LEGEND}

Figure 1. General morphology of the eugregarine Polyrhabdina pygospionis. Light differential interference (A, C-H) and phase contrast (B) microscopy.

All micrographs show gregarines with the anterior end facing up. A-B. Gamonts without the epimerite, slightly compressed with the coverslip; the nucleus $(\mathrm{N})$ has one nucleolus (n). C. Slightly compressed gamont with the epimerite (ep). D. Compressed gamont with the epimerite (ep). Note the collar (col) surrounding the epimerite base. Inset. Another compressed gamont with a seal-like (white arrow) structure under the pellicle (between black arrowheads) in the zone of separation of the epimerite (ep, heavily compressed) from the cell; scale bar is $10 \mu \mathrm{m}$. E. Two small gamonts glued to the host cell debris. Note nuclei (N) with three (left) and one (right) visible nucleoli (n). F. Young trophozoite being mechanically dislodged from the host cell. Note long tensile cords deriving from the destroyed epimerite (ep), the nucleus $(\mathrm{N})$ with two nucleoli (n). G-H. Epicytic crests (ec) of compressed gamonts: almost straight (G, adjacent crests are mostly parallel or in apposition to each other) and undulated $(\mathbf{H}$, a lot of areas where adjacent crests are in opposition to each other).

Figure 2. Fine structure of the eugregarine Polyrhabdina pygospionis. Scanning (A-E) and transmission (F-J) electron microscopy.

A. General morphology of a mechanically dislodged trophozoite with the epimerite (ep) having a collar (col) at the base and longitudinal epicytic crests (ec) on the cell surface. B-C. Epicytic crests of two trophozoites at high magnification: B, almost straight; C, undulated. D-E. The anterior end (D) and posterior end (E) of gamonts. Note the area where epicytic crests terminate. F. Cross-section in the middle of a gamont showing epicytic crests (ec), loops of the internal lamina (lp) under the bottom of grooves between the epicytic crests, and differentiation of the ectoplasm (ecto) from the rest of the cytoplasm with amylopectin granules (ag). G-H. Oblique sections of epicytic crests (ec). Note loops of the internal lamina (lp), a micropore (mp) on the wall of the epicytic crest, and presumably excreted mucous material (m) between crests. I-J. Transversal section of finger-like epicytic crests (ec); $\mathrm{J}$ is a detail of I at a higher magnification. Note the three-membrane pellicle consisting of the plasma membrane (pm) covered by glycocalyx and the inner membrane complex (IMC) underlain by the internal lamina (il). In the apex of each crest, there are 10-12 apical rippled dense structures (aa) between the plasma membrane and IMC, and 10-12 apical filaments (af) under the IMC.

Peer) reviewing PDF | (2020:12:56148:1:1:NEW 27 Jun 2021) 
1000 Figure 3. Attachment organelle (epimerite) of the eugregarine Polyrhabdina pygospionis. 1001 Scanning (A-C) and transmission (D-G) electron microscopy.

1002 A. Trophozoite (p) embedded in a piece of the ciliated intestinal epithelium of the host (h). B. 1003 Trophozoite (detail of Fig. 2A at a higher magnification) having the epimerite (ep) with a 1004 damaged apical surface membrane (am). Note longitudinal epicytic crests (ec) starting from 1005 under the collar (col) of the epimerite base. C. Micrograph showing a broken off epimerite 1006 embedded in the host intestinal epithelium (h). Note epicytic crests (ec) and the collar (col) at the 1007 epimerite base. D. Longitudinal section of a trophozoite (p), attached to the host cell (h) by the 1008 epimerite (ep), showing the differentiation of the peripheral cytoplasm into ectoplasm (ecto) poor in amylopectin granules (ag), epicytic crests (ec) starting from under the epimerite collar (col), internal lamina (il) under the gregarine pellicle, granular material (grm) of the ectoplasm at the epimerite base. Note the cortical zone (cz) of the epimerite filled with finely granular material. The infected host cell has vesicles with the material of heterogeneous electron density (vdm). Insert. A close up of part D at a higher magnification shows the terminal sections of the internal lamina (il) and the inner membrane complex (IMC), the narrow and deep circular gap (gp) underlain by a fibrillar layer (f), the distal end of the circular host cell fold (hf) covering the collar and embedded in the gap. Note granular material (grm) with short fibrils mainly congregated near the termini of the internal lamina and IMC and a kind of tight cell junction between plasma membranes of the parasite $\mathrm{AO}(\mathrm{pm})$ and the host epithelial cell (hm). $\mathbf{E}$. Longitudinal section of an epimerite embedded into an invagination of the host cell (h). Note the collar (col) and granular material (grm) at the epimerite base, fine electron-dense granular material in the cortical zone (cz) and the cytoplasm filled with amylopectin granules (ag) in the middle of the epimerite. F. Details of the epimerite collar (col) base. The cortical zone (cz) of the collar has fine electron-dense granular cytoplasm and is covered by the parasite plasma membrane (pm) and a thin circular host cell fold (hf), the distal end of which was embedded in the circular gap (gp) underlain by the fibrillar layer (f). Note the granular material (grm) and the termini of the internal lamina (il) and inner membrane complex (IMC). G. Contact zone between the host (h) and parasite (p) cells. Note the host (hm) and parasite (pm) plasma membranes, and fine electron-dense granular material in the epimerite cortical zone (cz).

Figure 4. General morphology of the eugregarine Polyrhabdina cf. spionis. Scanning electron microscopy.

A. Several trophozoites (p) attached to the host intestinal epithelium (h). B. Attached trophozoite (p) with the epimerite (ep) partly embedded into the host intestinal epithelium (h) and longitudinal epicytic crests $(\mathrm{ec})$. C. Details of a detached trophozoite with the preserved epimerite. Note that longitudinal epicytic crests (ec) emerge from under the collar (col) at the base of the globular epimerite (ep). D. Details of a mechanically dislodged trophozoite. The apical part of the epimerite (ep) embedded in the host cell was broken off, while the collar (col) at the epimerite base was retained.

\section{Figure 5. Bayesian tree of eugregarines inferred from the manually masked dataset of 94} SSU rDNA sequences and 1,574 sites under the $\mathbf{G T R}+\mathbf{F}+\mathbf{I}+\mathbf{G 8}$ model. Numbers at branches indicate Bayesian posterior probabilities (numerator) and ML bootstrap percentage (denominator). Black dots on the branches indicate Bayesian posterior probabilities and bootstrap percentages of 1.0 and $100 \%$, respectively. The newly obtained sequence of 
1045

1046

1047

1048

1049

1050

1051

1052

1053

1054

1055

1056

1057

1058

1059

1060

1061

1062

1063

1064

1065

1066

1067

1068

1069

1070

1071

1072

1073

1074

1075

1076

1077

1078

1079

1080

1081

1082

1083

1084

1085

1086

1087

1088

1089

1090

Polyrhabdina pygospionis is in bold. The names of major eugregarine lineages correspond to Simdyanov et al. 2017 and Cavalier-Smith, 2014.

Figure 6. Bayesian inference tree of eugregarines obtained from the manually masked dataset of 31 concatenated SSU, 5.8S, and LSU rDNA sequences (4,571 sites). Designations are the same as in Figure 5.

Figure 7. Diagram of the trophozoite structure of the eugregarine Polyrhabdina pygospionis attached to the host cell (not to scale). Abbreviations: col, epimerite collar; cz, cortical zone of epimerite cytoplasm; ec, epicytic crests; ep, epimerite; f, fibrillar layer; gp, circular gap at the epimerite base under the collar; grm, granular material of the ectoplasma; $h$, host cell; hf, host cell circular fold; hm, host plasma membrane; il, internal lamina of the parasite pellicle; IMC, inner membrane complex of the parasite pellicle; N, nucleus; $n$, nucleolus; $p$, parasite cell; pm, parasite plasma membrane.

\section{SUPPLEMENTARY MATERIAL}

SFigure 1. Gamonts of the eugregarine Polyrhabdina pygospionis detached from the host tissue. Light (A) and transmission electron (B) microscopy.

All micrographs show gamonts infected with metchnikovellid microsporidia (Mi, presporogonial stage development). A. Slightly compressed, detached gamont without the epimerite. Note the granular material (grm) in the ectoplasm of the anterior end and the nucleus (N). Differential interference contrast. B. Oblique longitudinal section through the anterior end of a detached gamont without the epimerite. Note the granular material (grm) in the ectoplasm (ecto) of the anterior end, epicytic crests (ec), the internal lamina (il), and the nucleus (N).

SFigure 2. Bayesian tree of eugregarines inferred from the manually masked dataset of 94 SSU rDNA sequences and 1,578 sites under the GTR+CAT+G8 model using PhyloBayes. Numbers at branches indicate Bayesian posterior probabilities. The newly obtained sequence of Polyrhabdina pygospionis is in bold.

\section{SFigure 3. Maximum likelihood trees.}

Maximum likelihood trees recovered from 1,578, 1,471, 1,366, 1,257, 1,126, and 828-site MAFFT E-INS-i + X-INS-i + trimAl and 1,574, 1,471, 1,366, 1,257, 1,126, and 828-site MAFFT E-INS- $\mathrm{i}$ - GUIDANCE2 alignments under GTR+F+I+G8 model with 1000 UFBoot replicates using IQ-TREE 2.1.2 (Minh et al., 2020). Numbers at branches indicate bootstrap (UFBoot) percentage supports.

SFigure 4. Bayesian tree of eugregarines inferred from the manually masked dataset of 65 SSU rDNA sequences and 1,574 sites under the GTR+F+I+G8 model. Numbers at branches indicate Bayesian posterior probabilities (numerator) and ML bootstrap percentage (denominator). Black dots on the branches indicate Bayesian posterior probabilities and bootstrap percentages of 1.0 and $95 \%$ and higher, respectively. The newly obtained sequence of Polyrhabdina pygospionis is in bold.

SFigure 5. R statistical computing. A. Principal component analysis of alignments based on bipartition support values obtained in the ML analyses with UFBoot; twenty bipartitions with the 
1091

1092

1093

1094

1095

1096

1097

1098

1099

1100

1101

1102

1103

1104

1105

1106

1107

1108

1109

1110

1111

1112

1113

1114

1115

1116

1117

1118

1119

1120

1121

1122

1123

1124

1125

1126

1127

1128

1129

1130

1131

most contributions to the principal components 1 and 2 are shown. Note that red dots formed a denser group than green or blues ones. Dot 828 indicates a critical level of data reduction at which the resolution of the trees is minimized. B. Histogram of contribution values in percentages for the first ten bipartitions shown in A. C - D. Comparison of two from the three alignments sets (Manual edited and GUIDANCE2; MAFT- X-INS-i is simalr to manual edited) in total tree length (C) and log likelihoods of trees (D); for both graphs, the maximum likelihood trees were used.

SFigure 6. Alignment and secondary structure model for the helix 17 region in the $18 S$ rRNAs of gregarines. Complementary nucleotides of the helices are shaded; the proposed evolutionary transition marked by a single nucleotide insertion and uniting the families Polyrhabdinidae and Trollidiidae is depicted schematically on the right; the corresponding scenario for the evolution of the helix 17 region within families Polyrhabdinidae and Trollidiidae is outlined in the tree (lower left) with at least 6 transitions: $\mathbf{1}$ - deletion of $1 \mathrm{bp}$ from the helix; 2 - expansion of the loop by 1 bp into the helix; 3 - 1 bp insertion in a single OTU; 4 transformation of the inner loop into a bulge; 5 - one nucleotide deletion in the apical part of the $3^{\prime}$-strand (resulting in an internal loop - $2 \mathrm{bp}$ - bulge); 6 - transformation of the inner loop into a bulge (resulting in a bulge $-2 \mathrm{bp}-\mathrm{a}$ bulge). The names of major eugregarine lineages correspond to Simdyanov et al. 2017 and Cavalier-Smith, 2014.

SVideo. Motility of Polyrhabdina pygospionis. Light microscopy, differential interference contrast. Real-time video $(15 \mathrm{sec})$ of a detached trophozoite (the cytoplasm is flowing out of the cell in the place of the dislodged epimerite), slightly compressed with the coverslip and gliding forward.

\section{STable 1. Morphometry of investigated eugregarines.}

Abbreviations: av, average; SD, standard deviation; $n$, number of measurements.

STable 2. Testing of possible compositions for the Ancoroidea. Anc - Ancoridae and Polyplicariidae, Poly - Polyrhabdinidae, Troll - Trollidiidae, Trich, Paralec - Trichotokara, Paralecudina and related environmental sequences, Ceph - Cephaloidiphoroidea, c-ELW Expected Likelihood Weight (Strimmer and Rambaut 2002), p-AU - p-value of approximately unbiased (AU) test (Shimodaira, 2002). Plus signs denote the $95 \%$ confidence sets. Minus signs denote significant exclusion. All tests performed 10000 resamplings using the RELL method in IQ-TREE 2.1.2 (Minh et al., 2020).

STable 3. Diagnostic characteristics of eugregarines of the genus Polyrhabdina Mingazinni, 1891. Abbreviations: '-', no data; '?', contradictory or vague description; '*', species examined by electron scanning microscopy; '**', species examined by electron scanning and transmission microscopy. The validation of the scientific names was conducted in the World Register of Marine Species (WoRMS). 


\section{Figure 1}

General morphology of the eugregarine Polyrhabdina pygospionis. Light differential interference $(A, C-H)$ and phase contrast (B) microscopy.

All micrographs show gregarines with the anterior end facing up. A-B. Gamonts without the epimerite, slightly compressed with the coverslip; the nucleus (N) has one nucleolus (n). C. Slightly compressed gamont with the epimerite (ep). D. Compressed gamont with the epimerite (ep). Note the collar (col) surrounding the epimerite base. Inset. Another compressed gamont with a seal-like (white arrow) structure under the pellicle (between black arrowheads) in the zone of separation of the epimerite (ep, heavily compressed) from the cell; scale bar is $10 \mu \mathrm{m}$. E. Two small gamonts glued to the host cell debris. Note nuclei (N) with three (left) and one (right) visible nucleoli (n). F. Young trophozoite being mechanically dislodged from the host cell. Note long tensile cords deriving from the destroyed epimerite (ep), the nucleus (N) with two nucleoli (n). G-H. Epicytic crests (ec) of compressed gamonts: almost straight (G, adjacent crests are mostly parallel or in apposition to each other) and undulated ( $\mathbf{H}$, a lot of areas where adjacent crests are in opposition to each other). 


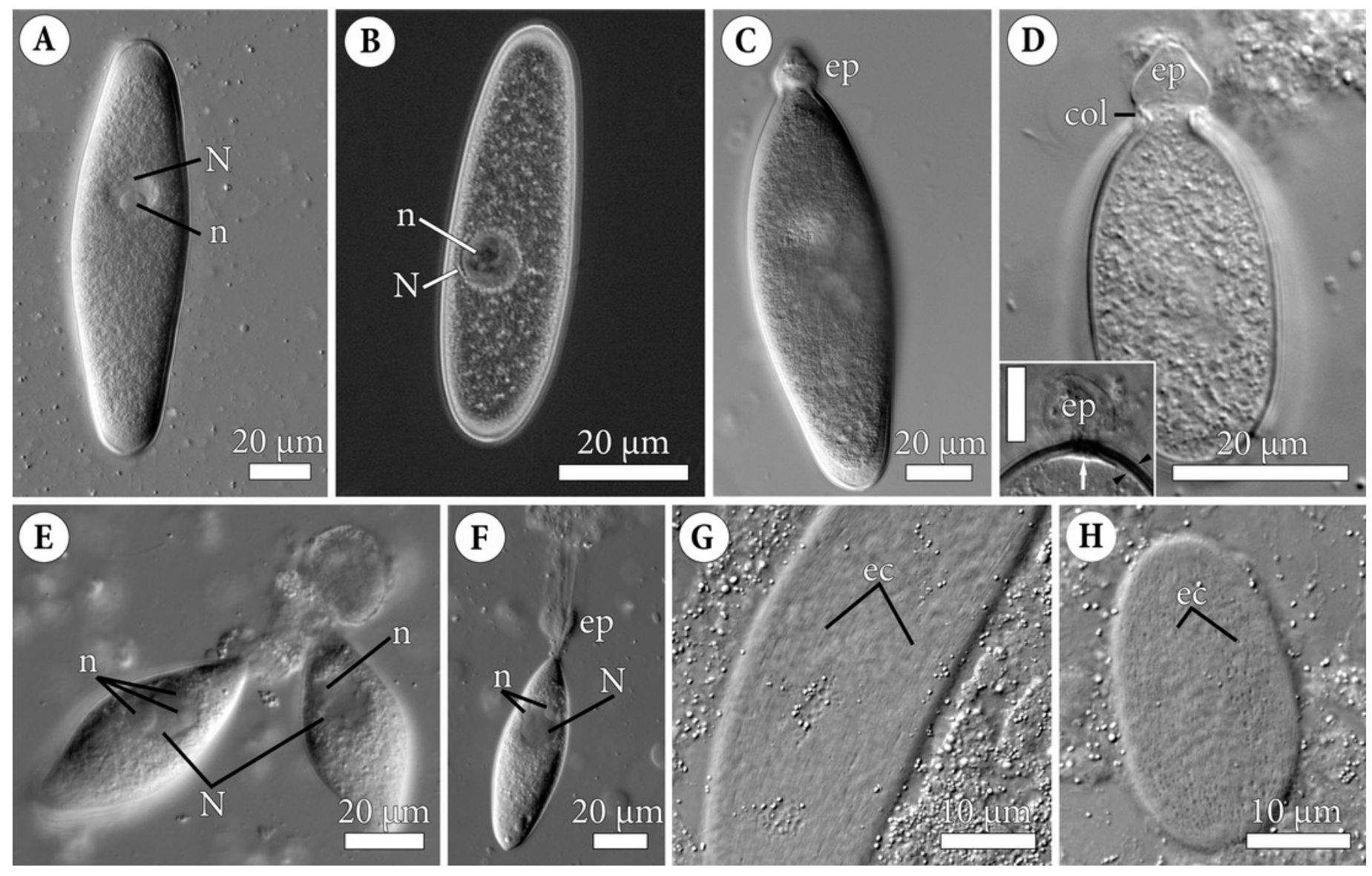




\section{Figure 2}

Fine structure of the eugregarine Polyrhabdina pygospionis. Scanning (A-E) and transmission (F-J) electron microscopy.

A. General morphology of a mechanically dislodged trophozoite with the epimerite (ep) having a collar (col) at the base and longitudinal epicytic crests (ec) on the cell surface. B-C. Epicytic crests of two trophozoites at high magnification: B, almost straight; C, undulated. D-

E. The anterior end (D) and posterior end (E) of gamonts. Note the area where epicytic crests terminate. F. Cross-section in the middle of a gamont showing epicytic crests (ec), loops of the internal lamina (Ip) under the bottom of grooves between the epicytic crests, and differentiation of the ectoplasm (ecto) from the rest of the cytoplasm with amylopectin granules (ag). G-H. Oblique sections of epicytic crests (ec). Note loops of the internal lamina (Ip), a micropore (mp) on the wall of the epicytic crest, and presumably excreted mucous material ( $\mathrm{m}$ ) between crests. I-J. Transversal section of finger-like epicytic crests (ec); J is a detail of I at a higher magnification. Note the three-membrane pellicle consisting of the plasma membrane $(\mathrm{pm})$ covered by glycocalyx and the inner membrane complex (IMC) underlain by the internal lamina (il). In the apex of each crest, there are 10-12 apical rippled dense structures (aa) between the plasma membrane and IMC, and 10-12 apical filaments (af) under the IMC. 

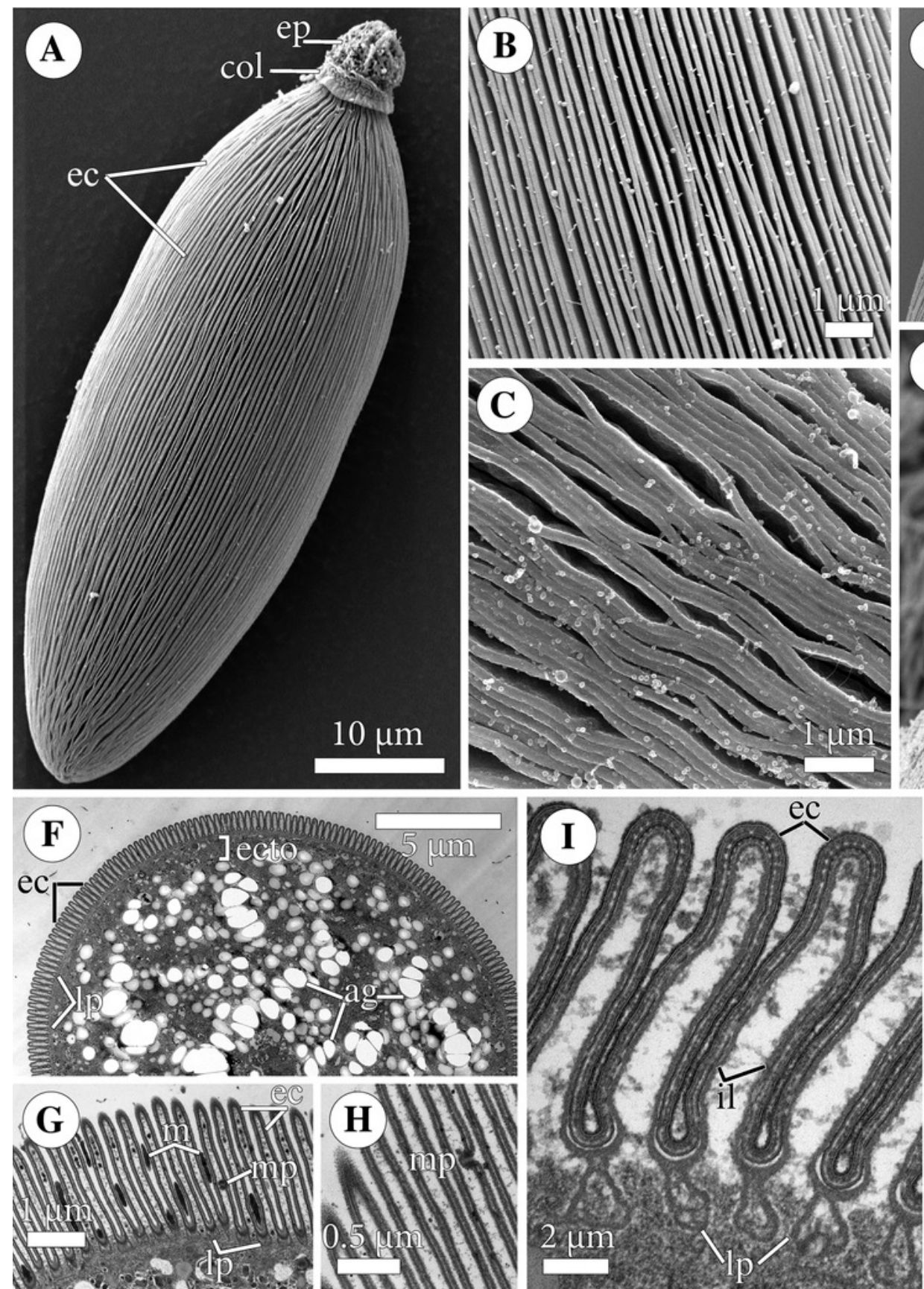
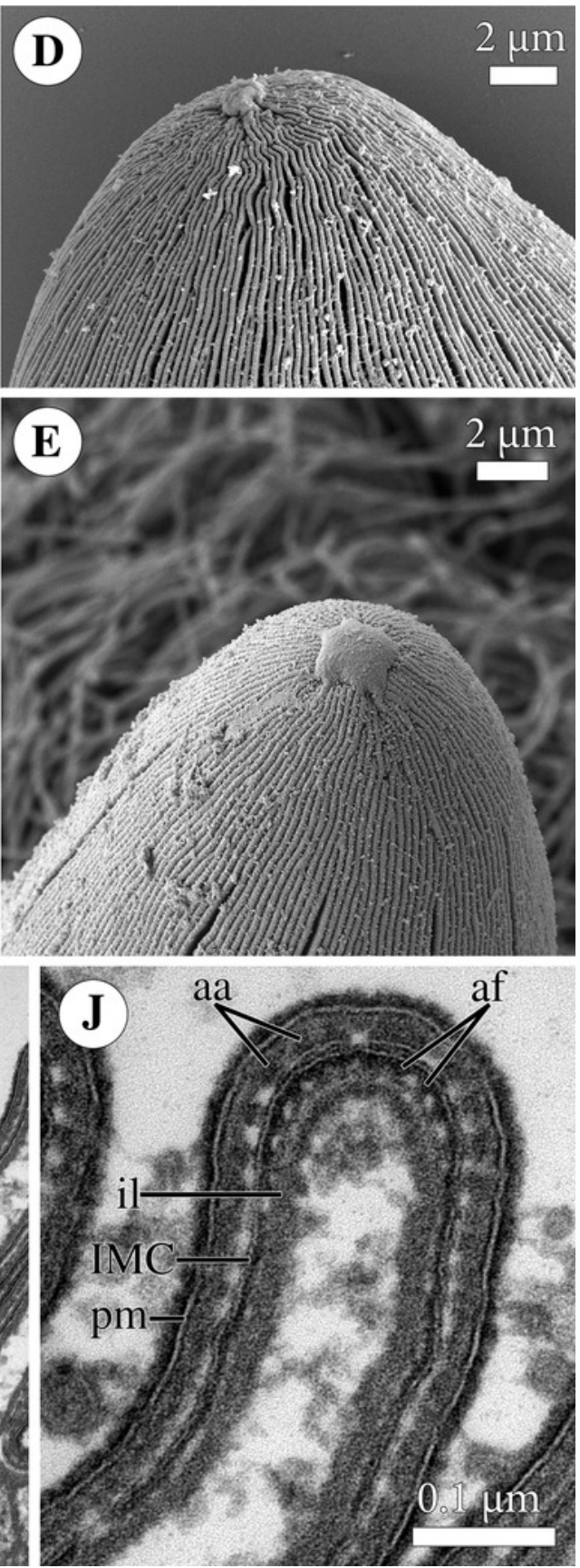


\section{Figure 3}

Attachment organelle (epimerite) of the eugregarine Polyrhabdina pygospionis. Scanning (A-C) and transmission (D-G) electron microscopy.

A. Trophozoite ( $p$ ) embedded in a piece of the ciliated intestinal epithelium of the host (h). B. Ttrophozoite (detail of Fig. 2A at a higher magnification) having the epimerite (ep) with a damaged apical surface membrane (am). Note longitudinal epicytic crests (ec) starting from under the collar (col) of the epimerite base. C. Micrograph showing a broken off epimerite embedded in the host intestinal epithelium (h). Note epicytic crests (ec) and the collar (col) at the epimerite base. D. Longitudinal section of a trophozoite ( $p)$, attached to the host cell (h) by the epimerite (ep), showing the differentiation of the peripheral cytoplasm into ectoplasm (ecto) poor in amylopectin granules (ag), epicytic crests (ec) starting from under the epimerite collar (col), internal lamina (il) under the gregarine pellicle, granular material ( $\mathrm{grm}$ ) of the ectoplasm at the epimerite base. Note the cortical zone (cz) of the epimerite filled with finely granular material. The infected host cell has vesicles with the material of heterogeneous electron density $(\mathrm{vdm})$. Insert. A close up of part $\mathrm{D}$ at a higher magnification shows the terminal sections of the internal lamina (il) and the inner membrane complex (IMC), the narrow and deep circular gap (gp) underlain by a fibrillar layer ( $\mathrm{f}$ ), the distal end of the circular host cell fold (hf) covering the collar and embedded in the gap. Note granular material ( $\mathrm{grm}$ ) with short fibrils mainly congregated near the termini of the internal lamina and IMC and a kind of tight cell junction between plasma membranes of the parasite $\mathrm{AO}(\mathrm{pm})$ and the host epithelial cell (hm). E. Longitudinal section of an epimerite embedded into an invagination of the host cell (h). Note the collar (col) and granular material (grm) at the epimerite base, fine electron-dense granular material in the cortical zone (cz) and the cytoplasm filled with amylopectin granules (ag) in the middle of the epimerite. F. Details of the epimerite collar (col) base. The cortical zone (cz) of the collar has fine electron-dense 
granular cytoplasm and is covered by the parasite plasma membrane (pm) and a thin circular host cell fold (hf), the distal end of which was embedded in the circular gap (gp) underlain by the fibrillar layer (f). Note the granular material ( $\mathrm{grm}$ ) and the termini of the internal lamina (il) and inner membrane complex (IMC). G. Contact zone between the host (h) and parasite (p) cells. Note the host $(\mathrm{hm})$ and parasite $(\mathrm{pm})$ plasma membranes, and fine electron-dense granular material in the epimerite cortical zone (cz). 

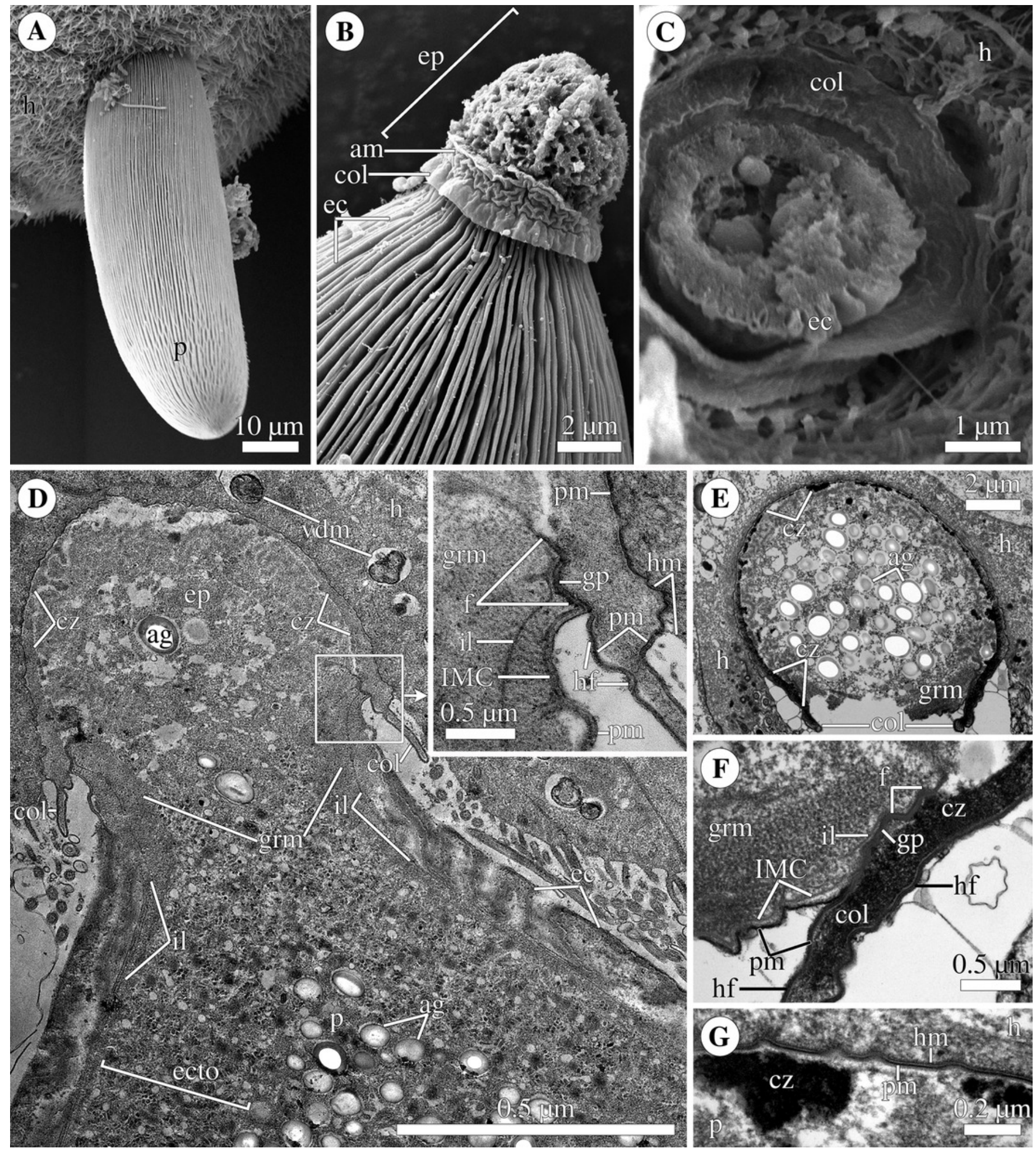


\section{Figure 4}

General morphology of the eugregarine Polyrhabdina cf. spionis. Scanning electron microscopy.
A. Several trophozoites $(p)$ attached to the host intestinal epithelium (h).
B. Attached
trophozoite ( $p$ ) with the epimerite (ep) partly embedded into the host intestinal epithelium

(h) and longitudinal epicytic crests (ec). C. Details of a detached trophozoite with the preserved epimerite. Note that longitudinal epicytic crests (ec) emerge from under the collar (col) at the base of the globular epimerite (ep). D. Details of a mechanically dislodged trophozoite. The apical part of the epimerite (ep) embedded in the host cell was broken off, while the collar (col) at the epimerite base was retained. 

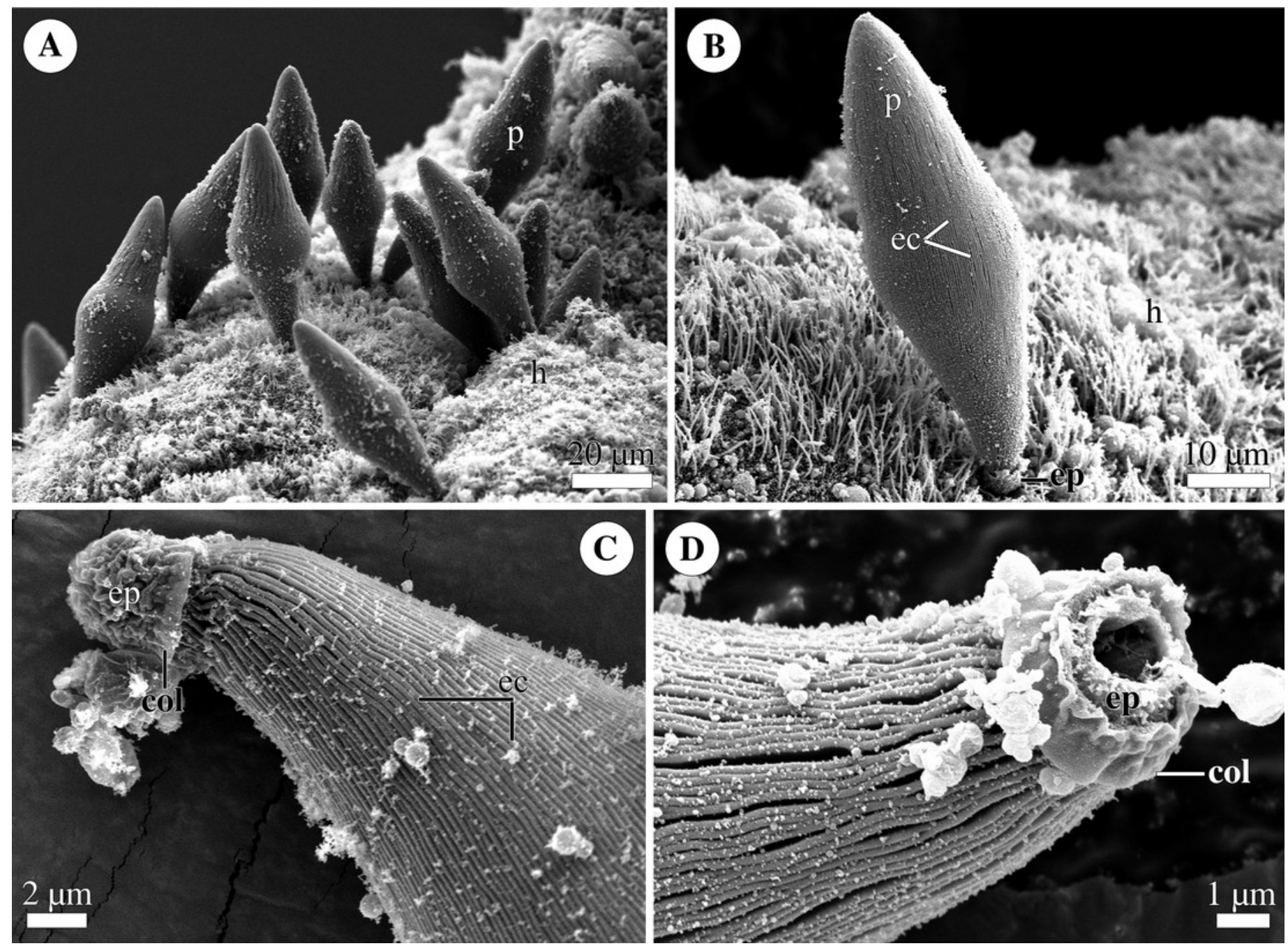


\section{Figure 5}

Bayesian tree of eugregarines inferred from the manually masked dataset of 94 SSU rDNA sequences and 1,574 sites under the $\mathrm{GTR}+\mathrm{F}+\mathrm{I}+\mathrm{G} 8$ model.

Numbers at branches indicate Bayesian posterior probabilities (numerator) and ML bootstrap percentage (denominator). Black dots on the branches indicate Bayesian posterior probabilities and bootstrap percentages of 1.0 and $100 \%$, respectively. The newly obtained sequence of Polyrhabdina pygospionis is in bold. The names of major eugregarine lineages correspond to Simdyanov et al. 2017 and Cavalier-Smith, 2014. 


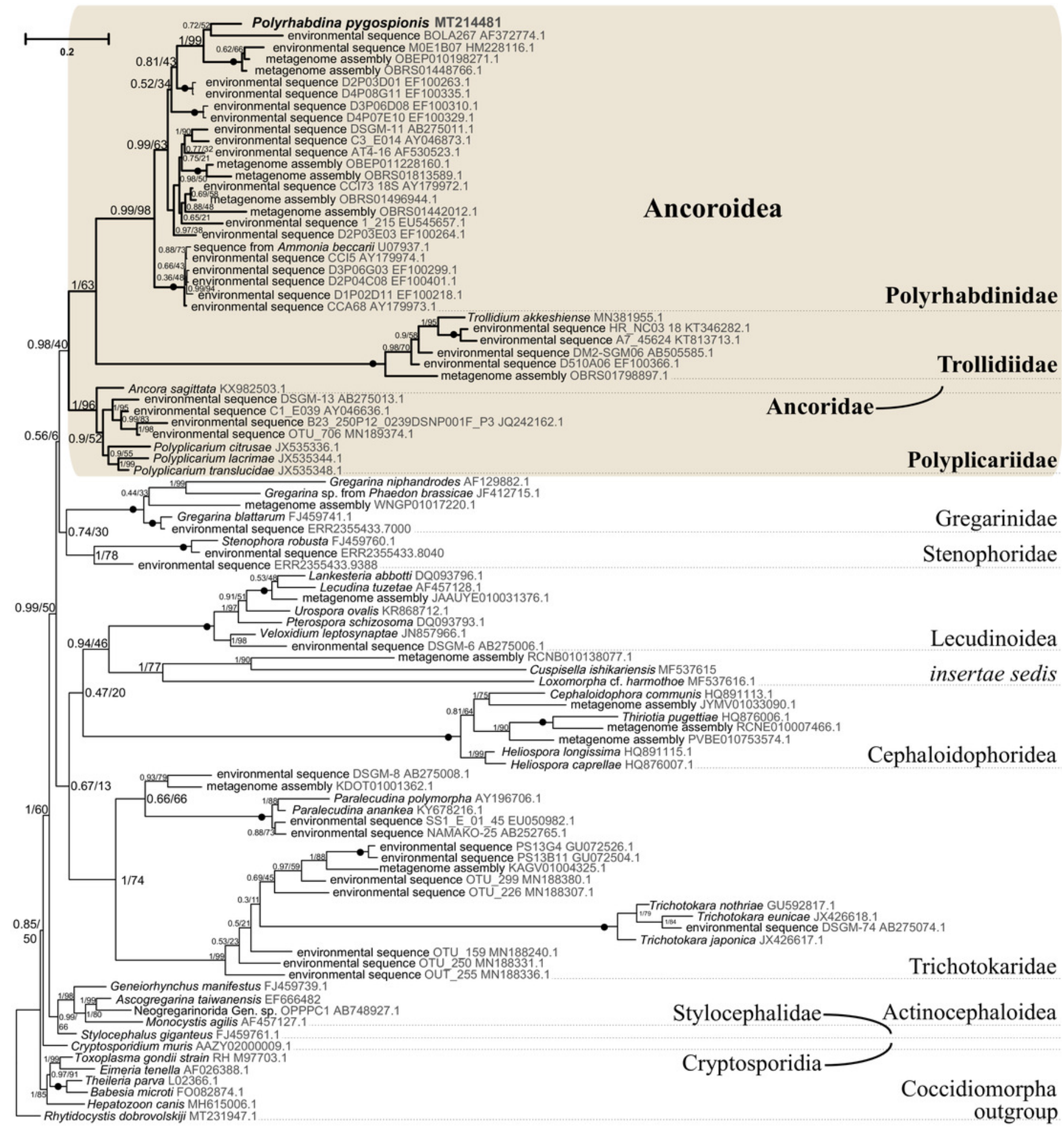




\section{Figure 6}

Bayesian inference tree of eugregarines obtained from the manually masked dataset of 31 concatenated SSU, 5.8S, and LSU rDNA sequences (4,571 sites).

Designations are the same as in Figure 5.

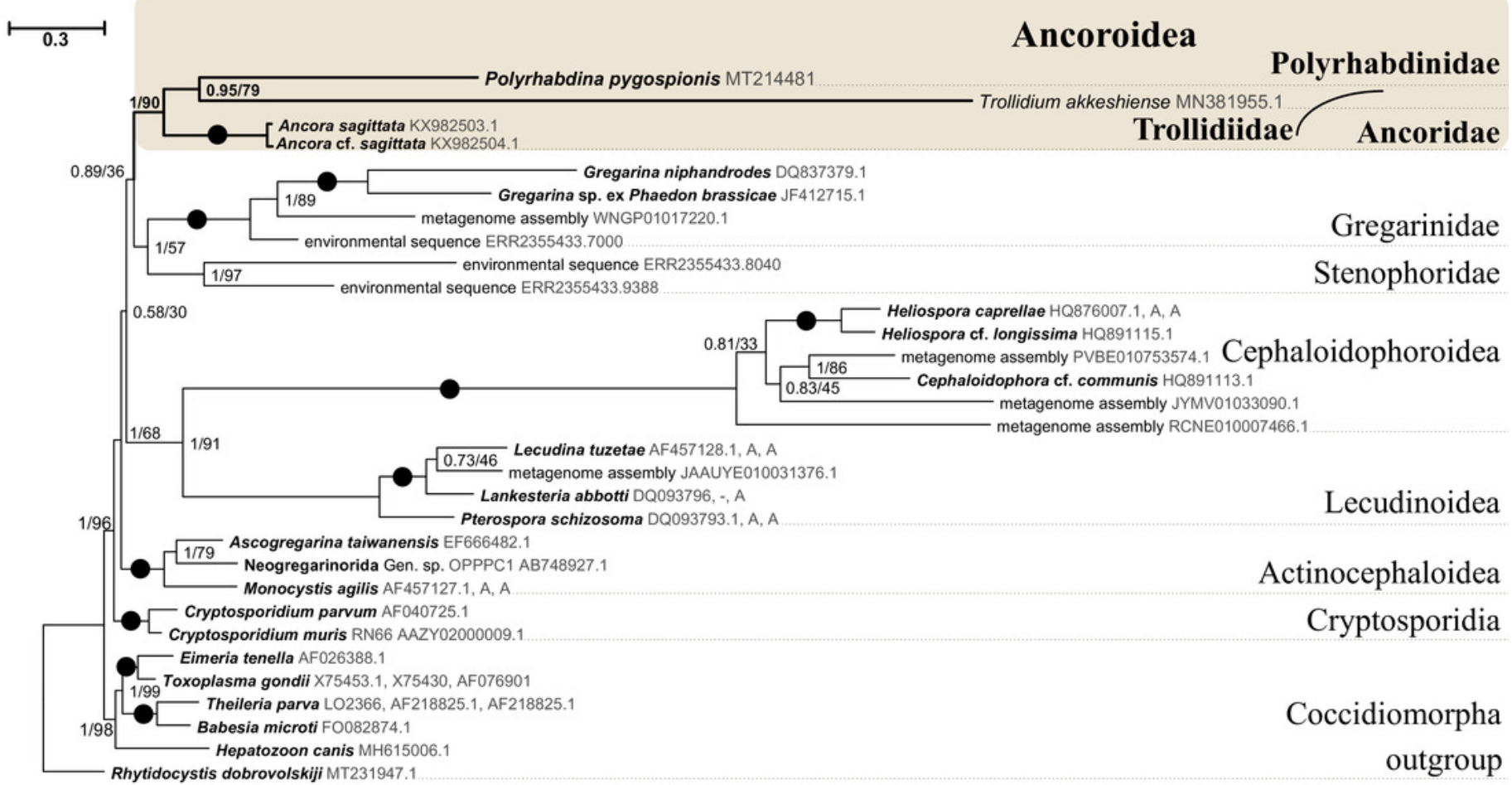




\section{Figure 7}

Diagram of the trophozoite structure of the eugregarine Polyrhabdina pygospionis attached to the host cell (not to scale).

Abbreviations: col, epimerite collar; cz, cortical zone of epimerite cytoplasm; ec, epicytic crests; ep, epimerite; f, fibrillar layer; gp, circular gap at the epimerite base under the collar; grm, granular material of the ectoplasma; h, host cell; hf, host cell circular fold; hm, host plasma membrane; il, internal lamina of the parasite pellicle; IMC, inner membrane complex of the parasite pellicle; $\mathrm{N}$, nucleus; $\mathrm{n}$, nucleolus; $\mathrm{p}$, parasite cell; pm, parasite plasma membrane.

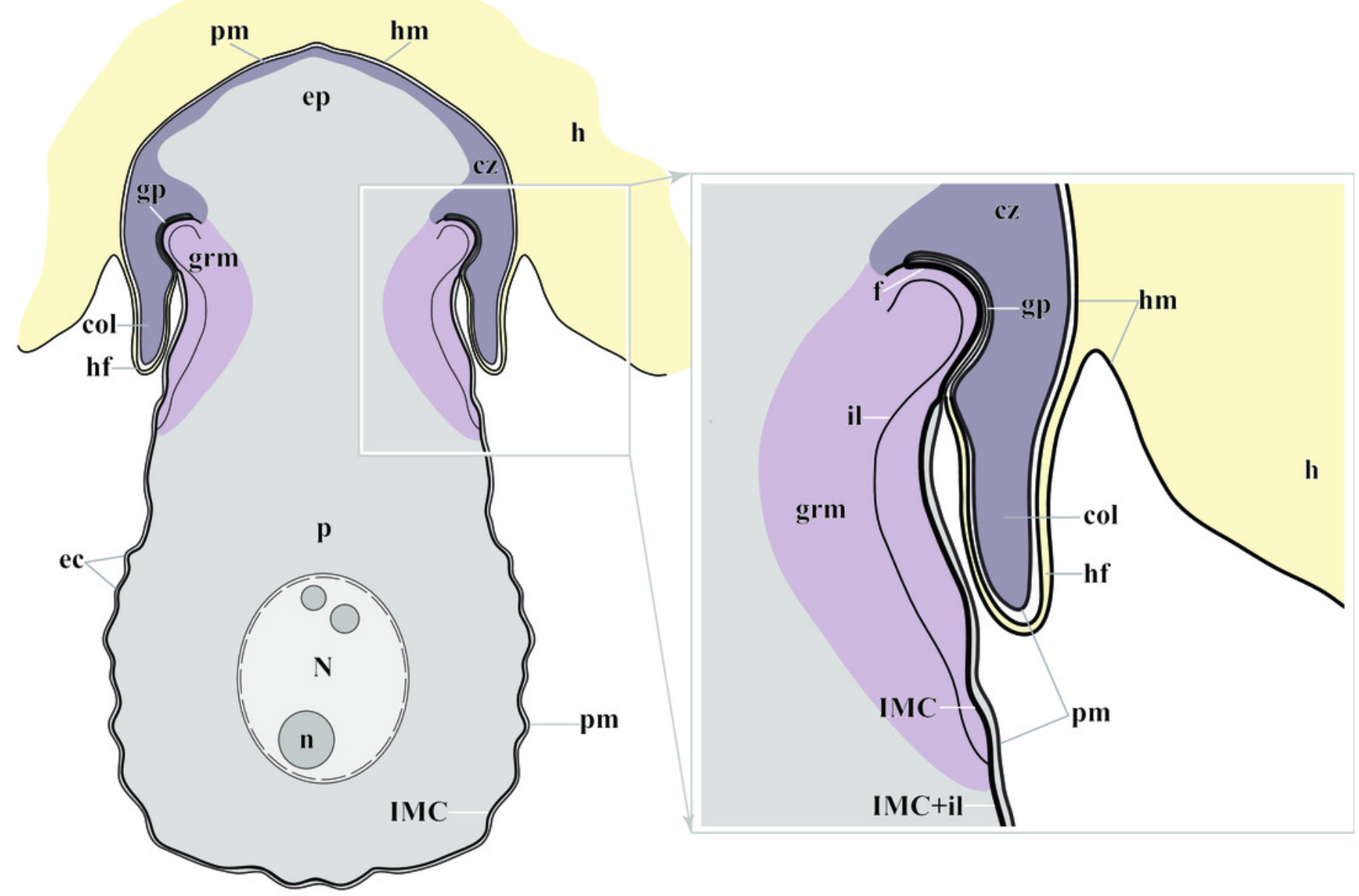

